\title{
Liquidity Supply across Multiple Trading Venues ${ }^{1}$
}

\author{
Laurence Lescourret \\ ESSEC Business School ${ }^{2}$
}

Sophie Moinas

Toulouse School of Economics (Université de Toulouse and CRM) ${ }^{3}$

\footnotetext{
${ }^{1}$ We are grateful to Thierry Foucault, Bruno Biais, Giovanni Cespa, José Miguel Gaspar, Carole Gresse, Stefano Lovo, and seminar participants at the Dauphine Workshop on Financial Market Quality, the EIF Scientific Morning Conference, the ESSEC Brown Bag and the CSEF seminar for providing useful comments. We especially thank Patrick Hazart for providing us Euronext data. Laurence Lescourret is research fellow at CREST. Financial support from the EIF and the ANR (ANR-09-JCJC-0139- 01 and ANR-10-JCJC-1810-01) is gratefully acknowledged. Of course, all errors or omissions are ours.

${ }^{2}$ ESSEC Business School, Avenue Bernard Hirsch, 95021 Cergy-Pontoise, France. E-mail address: lescourret@essec.edu. Phone: +33 1344333 62. Fax: +33 134433212.

${ }^{3}$ Université de Toulouse, Place Anatole France, 31000 Toulouse, France. E-mail address: sophie.moinas@ut-capitole.fr
} 


\begin{abstract}
Recent regulatory changes have fragmented the trading of financial securities, giving rise to the emergence of "global" dealers, that is, intermediaries making the market simultaneously across more than one trading venue. We develop an inventory model in which two risk-averse global dealers compete to absorb part or the totality of an order flow that fragments between two venues. We show that fragmentation may lead to a better allocation of risks among dealers, which may result in lower transaction costs. We also show that bid-ask spreads in a venue depend on the sign and size of the order flow routed to the other venue. We test these predictions using proprietary data from Euronext on multi-listed firms. First, we document the existence of a pool of traders who split their liquidity supply across the different order books, and we find that market spreads are significantly impacted by the divergence of dealers' global inventory. Second, we show that market spreads are significantly related to the size and the direction of order flow routed to the other venue, consistently with our predictions.
\end{abstract}

Keywords: Multi-market trading, market fragmentation, inventory, bid-ask spreads EFM Classification code: 360. 


\section{Introduction}

In the last decade, falling technology costs and changes in regulation both in the U.S. (RegNMS) and in Europe (MiFID) have fostered the proliferation of alternative trading venues, giving rise to the emergence of "global" dealers, that is, intermediaries making the market simultaneously across more than one trading venue. Getco for instance trades NYSE-listed securities in ARCA, GETMATCHED, BATS-Z, NYSE, EDGA, NASDAQ, BATS-Y, BX, LIGHTPOOL, and DEUTSCHE BANK. Recent empirical evidence (e.g. Menkveld, 2012, Brogaard, 2011, Jovanovic and Menkveld, 2011, van Kervel, 2012) further shows that high frequency traders, namely financial institutions which have invested in high speed capacity, informally undertake this role by engaging in market making across different electronic trading venues. In this paper, we develop an inventory model to analyze how competing dealers strategically supply liquidity across multiple markets. We then test the predictions of our model using a proprietary dataset from Euronext on multitraded stocks, in which we can identify financial institutions involved in multi-market market making.

Intuitively, fragmentation promotes price competition and a potential sharing of the order flow creates room for a better allocation of risks among dealers, which may induce them to post more aggressive prices. Conversely, the opportunity to share order flow may also enable dealers to specialize in one market, which lowers their incentives to post aggressive prices. We formalize this intuition using an inventory model based on Ho and Stoll (1983), in which order flow fragments between two trading venues. Two risk averse dealers have to simultaneously post prices to absorb the incoming fraction of the order flow in both markets. We introduce an asymmetry by assuming that the venue termed as the dominant market receives a larger portion of the order flow than the alternative venue termed as the satellite market. For the ease of exposition, we assume that the part sent to the dominant market is net buying, while the part sent to the satellite market may be either net-buying or net-selling.

We show that the execution of the order flow may remain fragmented if each dealer executes only one part of the fragmented order flow ("sharing"). It may also be the case that a single dealer executes the total fragmented order flow ("consolidation"). This result depends on whether order flows sent to the dominant and the satellite market have the 
same sign or not, and on how divergent the dealers' inventory positions are from each other.

When order flows have the same sign, a dealer faces a "dual liability risk": in case his quotes are hit, the dealer executes a cumulated buy transaction. We could have expected a premium due to this additional risk, leading to larger spreads. This may not be the case. Actually, the dealer consolidates the fragmented order flow by posting competitive quotes when her inventory position is extreme relative to her opponent. In this case, executing the total order flow is desirable to reduce her inventory exposure. When her inventory position is close to her opponent, she may choose to execute only the part of the fragmented order flow which best reduces her inventory risk, thus specializing in one market.

By contrast, when order flow have opposite signs, the longer dealer consolidates the fragmented order flow only when her inventory position is close to her opponent. The cumulated transaction in both market creates an "offsetting" effect, which may not be desirable. For instance, when the dealer is in an extreme long position relative to the other, she is reluctant to add more inventory by executing an incoming sell order. She will thus post attractive competitive prices only in the market receiving the buy order flow to reduce her inventory exposure. Conversely, when dealers' inventory positions are close, dealers are less able to post very competitive prices. In particular, if the total order flow is net buying, the dealer with the longer position, but close to her opponent, prefers to execute orders with a small price impact, and thus prefers to trade the total fragmented order flow to benefit from the offsetting effect.

Overall we show that our results depend strongly on the possibility of dealers to compete only on one part of the order flow, through the existence of multiple venues. In our set up, fragmentation surprisingly may lead to lower expected spreads compared to the case when order flow consolidates in a single market (Ho and Stoll, 1983).

The model yields crisp predictions about the average spreads in the presence of multiple venues: expected spreads in one venue vary with the simultaneity, the size, the sign, and the interaction between the sign and the size of the order flow routed to the alternative venue.

We test these predictions using a proprietary dataset on multi-traded stocks from Euronext on a four-month period in 2007. When Euronext was created in 2000 as a 
result of the merger of three European Stock Exchanges, namely Paris, Brussels and Amsterdam, the stocks which used to be multi-listed in different Exchanges for various reasons fell into the Euronext jurisdiction. Within Euronext, trading rules in all markets have been harmonized and structured on the Paris Bourse limit order book model, while remaining separated order books with price-time priority enforced within each market, but not across markets, until 2009. Besides, during that period (that is, before the implementation of MiFID in November 2007), Euronext was virtually collecting all the trades. ${ }^{1}$ For these reasons, Euronext provides an excellent laboratory, in line with our theoretical framework, to test our predictions. In our dataset, orders and trades sent to or executed in any limit order book are flagged with a unique ID code and the account used by the financial institution. This enables us to identify 42 global dealers, that is, members acting either as proprietary traders or as exchange-regulated market makers, and who trade at least once every month in each of the two exchanges on which the stock is traded. Due to the supremacy of Euronext, our reconstitution of dealers' end-of-day positions, that accounts for their trades in all the limit order books of Euronext, is a good proxy for dealers' global inventories. Our empirical analysis investigates the link between the behavior of these global dealers, and market liquidity. We first document that the more divergent the inventories across members (i.e., the higher the standard deviation of relative inventories), the more competitive the quotes they place, and the smaller the spreads. This result suggests that inventory risk premia may be a significant component of spreads in limit order markets. We also find that the size of the order flow sent to the dominant market significantly impacts the spreads in the satellite market. Finally, we show that the impact of the sign of order flows correlation is statistically significant on spreads. These results are consistent with the predictions of our inventory model across venues. This suggests that global dealers consolidate fragmented markets through their inventory management.

Our empirical analysis is motivated by a new theoretical approach to multi-market trading. Traditional models including Pagano, 1989, Chowdry and Nanda, 1991, Bernhardt and Hughson, 1997, Easley, Kiefer and O’Hara, 1996, and Foucault and Menkveld, 2008 assume that quotes are competitively set by independent pools of Bayesian market

\footnotetext{
${ }^{1}$ For instance, Gresse, 2012 or Degryse, De Jong, and van Kervel, 2011 report a market share of more than $95 \%$ for French and Dutch stocks respectively over our sample period.
} 
makers in multiple markets to satisfy the zero-profit condition. They focus on the routing or order splitting decisions of strategic liquidity demanders, who can either be informed or not. Naturally, these strategies are anticipated by the liquidity suppliers who adjust their quotes in the different markets according to their beliefs. We instead exogenously fix order flows routed towards each market to focus on the inter-dependent quoting strategies of market makers in multiple markets. As Seppi, 1997 and Parlour and Seppi, 2003, we model competition for order flow based on liquidity provision when liquidity suppliers are not perfectly competitive. Parlour and Seppi, 2003 extend the model proposed by Seppi, 1997 to analyze the quotes set by a monopolist specialist competing against a competitive order book, and incorporate liquidity demander's optimal splitting. The specialist has a timing advantage over the value traders who post limit orders in the limit order book. In contrast, the market makers in our model post their quotes simultaneously. We show that risk averse liquidity suppliers using multi-market strategies correlate the best quotes in multiple trading venues, even in the absence of private information.

Few empirical papers focus on the extent to which traders exploit multi-market environments. Menkveld, 2008 and Halling, Moulton, and Panayides, 2013 focus on how investors adjust their trading strategies to multi-trading. In contrast, we investigate how liquidity suppliers deal with a multi-market environment, and our empirical analysis is most closely related to van Kervel, 2012, and Jovanovic and Menkveld, 2011. van Kervel, 2012 finds that trades on the most active venues for 10 FTSE100 stocks are often followed by immediate cancellations of limit orders on competing venues, which would be expected in the presence of a global dealers facing a dual liability risk. Jovanovic and Menkveld, 2011 statistically identify a global dealer actively trading across Euronext and Chi-X, and find that the participation of this dealer has an impact on spreads and volumes. Both findings are in line with our theoretical predictions and complement our empirical analysis. Each institution in our sample is identified by a unique ID across the multiple limit order books of Euronext. Empirically, this enables us to deepen the analysis and to precisely analyze the quoting strategies of all the members who exploit the multi-market environment.

The paper is organized as follows. Section 2 describes the model. Section 3 investigates the price formation when order flow fragments between two venues and derives some empirical predictions. Section 4 describes the data, provides summary statistics and tests 
the main prediction. Section 5 concludes the paper.

\section{The Model}

The objective is to examine how the presence of two competing trading venues influences dealers' quoting strategy.

\subsection{The basic setting}

We consider the market for a risky asset, whose final cash flow is a normal random variable $\tilde{v}$ characterized by an expected value $\mu$ and a variance $\sigma^{2}$. There are two types of market participants: investors who demand liquidity and dealers who supply liquidity. Liquidity is exogenously demanded by investors who submit market orders. Liquidity is supplied by risk-averse dealers who stand ready to execute incoming market orders at their bid or ask quote against their own inventory.

\subsubsection{Dealers' reservation price and inventory holding cost}

We focus on the behavior of two strategic dealers who compete to post the most competitive price so as to execute incoming order flow. Dealers 1 and 2 have the following common CARA utility function:

$$
u(w)=-\exp (-\rho w)
$$

where $\rho$ is the risk aversion, and $w$ the terminal wealth of a dealer.

Dealers differ in their (random) inventory position of the risky asset, $\tilde{I}_{i}$. Accordingly, dealers have heterogeneous reservation prices, defined by equating expected utilities $E U\left(Q, r_{i}\right)=E U\left(0, r_{i}\right)$, where $U\left(Q, r_{i}\right)$ indicates that dealer in position $I_{i}$ trades $Q$ shares at price $r_{i}$. It follows that: ${ }^{2}$

$$
r_{i}(Q)=\mu+\frac{\rho \sigma^{2}}{2}\left(Q-2 I_{i}\right), i=1,2
$$

where $Q$ is the incoming signed order flow to accommodate, and $I_{i}$ is the realization of the

\footnotetext{
${ }^{2}$ This result follows Ho and Stoll's (1983) Proposition 1.
} 
random variable $\tilde{I}_{i}$ uniformly distributed on $\left[I_{d}, I_{u}\right]$. We suppose that $Q>0$ when it is a buy incoming order flow, while $Q<0$ when it is a sell incoming order flow. ${ }^{3}$ Consider that $\left(\mu-\rho \sigma^{2} I_{i}\right)$ is the marginal valuation of dealer $i$ for the risky asset, as in Biais, Glosten and Spatt (2005). Note that the marginal valuation depends on the risk for dealer $i$ of holding an inventory position. Hence, a dealer in a long position is reluctant to increase his exposure to inventory risk by adding more inventory and posts relatively low ask and bid prices to encourage selling operations. The second component of reservation prices $\left(\left(\rho \sigma^{2} / 2\right) Q\right)$ represents the price impact of trades and, thus, is increasing in trade size: larger buy orders will drive dealer $i$ ' selling price more above dealer $i$ 's marginal valuation (and vice versa). Note also that we can, equivalently, consider that the reservation price $r_{i}(Q)$ is a uniform random variable defined on $\left[r_{u}(Q), r_{d}(Q)\right]$. All random variables are independent and their distributions are common knowledge.

\subsubsection{Fragmentation of the order flow}

We suppose that the order flow may be routed to two different venues, denoted $D$ and $S$. The part sent to venue $D$, denoted $Q_{D}$, is larger than that sent to venue $S$, i.e. $\left|Q_{D}\right|>\left|Q_{S}\right|$. Due to this asymmetry, we term market $D$ as the dominant market, and market $S$ as the satellite market. We restrict our analysis to the case where order flow sent to $D$ is a buy order flow, $Q_{D} \geq 0$, while $Q_{S}$ might be either sell or buy order flow: $Q_{S} \geq 0$ or $Q_{S} \leq 0 .^{4}$

\subsubsection{The timing of the game and dealers' payoffs}

At date 1 , dealer $i$ is endowed with an initial inventory position $I_{i}$. At date 2, some liquidity traders send their order flow to venue $D$ while some others send their order flow to venue $S$. At date 3 and conditional on observing $Q_{D}$ and $Q_{S}$, dealers post simultaneously their quotes in venues $D$ to execute $Q_{D}$ and in $S$ to execute $Q_{S}$. The dealer who posts the lowest ask price in venue $D$ executes $Q_{D}$, while the dealer with the lowest ask (respectively the highest bid) in market $S$ executes $Q_{S}>0$ (resp. $\left.Q_{S}<0\right)$, depending on the sign of the order flow sent to venue $S$.

\footnotetext{
${ }^{3}$ Note that $r_{i}=\mu-\frac{\rho \sigma^{2}}{2}\left(-Q+2 I_{i}\right)$ when $Q<0$.

${ }^{4}$ Our predictions are derived from a net-buying order flow $\left(Q_{D}+Q_{S}>0\right)$. Symmetric results are obtained for a net-selling order flow.
} 
As in Biais (1993), the utility function of dealers given in (1) is linearized ${ }^{5}$, under the assumption $Q_{D}<I_{u}-I_{d}{ }^{6}$ Reservation prices however depend on risk aversion.

Let us denote $a_{i}^{m}$ (resp. $b_{i}^{m}$ ) the ask (resp. bid) price set by dealer $i \in\{1,2\}$ in market $m \in\{D, S\}$. Then, when $Q_{S}>0$, dealer $i$ 's trading profit is simply given by:

$v_{i}\left(a_{1}^{D}, a_{2}^{D}, a_{1}^{S}, a_{2}^{S}\right)=\left\{\begin{array}{cl}a_{i}^{D} Q_{D}+a_{i}^{S} Q_{S}-r_{i}\left(Q_{D}+Q_{S}\right)\left(Q_{D}+Q_{S}\right) & \text { if } a_{i}^{D}<a_{-i}^{D} \text { and } a_{i}^{S}<a_{-i}^{S}, \\ \left(a_{i}^{D}-r_{i}\left(Q_{D}\right)\right) Q_{D} & \text { if } a_{i}^{D}<a_{-i}^{D} \text { and } a_{i}^{S}>a_{-i}^{S}, \\ \left(a_{i}^{S}-r_{i}\left(Q_{S}\right)\right) Q_{S} & \text { if } a_{i}^{D}>a_{-i}^{D} \text { and } a_{i}^{S}<a_{-i}^{S}, \\ 0 & \text { if } a_{i}^{D}>a_{-i}^{D} \text { and } a_{i}^{S}>a_{-i}^{S} .\end{array}\right.$

When $Q_{S}<0$, dealer $i$ 's trading profit is given by:

$v_{i}\left(a_{1}^{D}, a_{2}^{D}, b_{1}^{S}, b_{2}^{S}\right)=\left\{\begin{array}{cl}a_{i}^{D} Q_{D}-b_{i}^{S}\left|Q_{S}\right|-r_{i}\left(Q_{D}+Q_{S}\right)\left(Q_{D}+Q_{S}\right) & \text { if } a_{i}^{D}<a_{-i}^{D} \text { and } b_{i}^{S}>b_{-i}^{S}, \\ \left(a_{i}^{D}-r_{i}\left(Q_{D}\right)\right) Q_{D} & \text { if } a_{i}^{D}<a_{-i}^{D} \text { and } b_{i}^{S}<b_{-i}^{S}, \\ \left(r_{i}\left(Q_{S}\right)-b_{i}^{S}\right)\left|Q_{S}\right| & \text { if } a_{i}^{D}>a_{-i}^{D} \text { and } b_{i}^{S}>b_{-i}^{S}, \\ 0 & \text { if } a_{i}^{D}>a_{-i}^{D} \text { and } b_{i}^{S}<b_{-i}^{S} .\end{array}\right.$

In this paper, we suppose that dealers observe competitors' quotes, as if markets were transparent. This set up was first studied by Ho and Stoll (1983). We also suppose, for ease of exposition, that the dealer endowed with the longer inventory position is dealer 1 , i.e. $I_{1}>I_{2}$.

Figure 1 represents the extensive form of quoting game in market $m$, conditional on dealers observing a non-zero order flow sent to this venue. We call $\lambda_{-m}$ the ex ante probability with which the order flow sent simultaneously to the alternative market $-m$ is non-zero, and $\gamma$ the ex ante probability that simultaneous non-zero order flows have the same sign. ${ }^{7}$ We focus on the case where order flows routed to the two venues are non-zero. The equilibrium strategies when no order flow is routed to the alternative trading venue are obtained at the limit when $Q_{-m} \rightarrow 0$ and are similar to those obtained in standard inventory models (e.g. Ho and Stoll, 1981, 1983). In the next section, we analyze the two

\footnotetext{
${ }^{5}$ For tractability reasons, the direct effect of risk aversion on preferences is removed by using the first order linear approximation proposed by Biais (1993).

${ }^{6}$ The assumption $Q_{D}<I_{u}-I_{d}$ also guarantees that dealer $i(i=1,2)$ has a probability to post the best price in market $m(m=D, S)$ which is strictly greater than 0 and strictly lower than 1 .

${ }^{7}$ Assuming that order flows in markets $D$ and $S$ are equally likely to be on the buy or sell side, and conditional on order flows in both markets being non-zero, the correlation coefficient of order flows is $2 \gamma-1$.
} 
polar cases, first when order flows have the same sign (e.g. subgame (1+) in Figure 1), then when they have opposite directions (e.g. subgames (1-) for market $D$ and $(3-)$ for market $S$ in Figure 1).

\section{$3 \quad$ Equilibrium quotes in fragmented markets}

Our model considers that order flow fragments between two trading venues: a net-buy order is routed to the dominant market, while a smaller (in absolute value) net-buy or net-sell order is routed to the satellite market. Each dealer must simultaneously choose an ask quote to execute $Q_{D}$ in market $D$, and either an ask or a bid price to execute $Q_{S}$ in market $S$. If order flow would consolidate in a single market, we would be back to the case analyzed by Ho and Stoll (1983), in which the dealer with the longer inventory position (dealer 1 by assumption) posts the most competitive ask quote, by quoting the second lowest reservation price $\left(\left(a^{H S}\right)^{*}=r_{2}\left(Q_{D}+Q_{S}\right)-\varepsilon\right.$, in our case). This section analyzes how fragmentation of order flow alters this result.

\subsection{Preliminary results}

Standard inventory models predict that the dealer endowed with the longer position is more eager to absorb the net buy order flow $\left(Q_{D}+Q_{S}\right)$. Lemma 1 below shows however that this dealer might prefer to trade only a part of it and let her competitor trade the other part.

Lemma 1 Assume that $I_{1}>I_{2}$ and that $Q_{D}+Q_{S}>0$.

1. If $\left(I_{1}-I_{2}-Q_{D}\right) Q_{S}<0$, and if an equilibrium exists, then it is such that dealers share the fragmented order flow. Conversely, if $\left(I_{1}-I_{2}-Q_{D}\right) Q_{S}>0$, and if an equilibrium exists, then it is characterized by the consolidation of the fragmented order flow.

2. If there exists an equilibrium such that dealers share the order flow, then the longer dealer executes the larger component $Q_{D}$ and the shorter dealer executes the smaller component $Q_{S}$ of the fragmented order flow. If there exists an equilibrium characterized by the consolidation of the fragmented order flow, then the longer dealer trades the total net-buying order flow, $Q_{D}+Q_{S}$. 
At equilibrium, either the execution of the order flow remains fragmented if dealers share it, or it is consolidated when executed by a single dealer. The outcome depends both on the sign of the order flow sent to market $S$ (relative to that routed to market $D$ ), and on the degree of divergence between dealers' inventory position. First, when $Q_{D}$ and $Q_{S}$ have the same sign, order flows in markets $D$ and $S$ are substitutes: the marginal gain of trading $Q_{D}>0$ when the dealer also trades $Q_{S}>0$ is lower than when he does not trade $Q_{S}$. Conversely, when order flows have opposite sign, they are complements. ${ }^{8}$ Another view is to observe that dealers face a cumulative effect when they simultaneously execute trades of the same sign, and face an offsetting effect when they execute trades of opposite sign. Because of these complementarity or substitution effects (cumulative vs. offsetting effects), dealers' preferences to trade only a part versus the total fragmented order flow vary with the sign of $Q_{S}$ relative to $Q_{D}$.

Second, the degree of divergence between dealers' inventory expresses the competitiveness of dealers' quotes in both markets and thus dealers' ability to execute the total order flow or only a part of it. When the divergence is low (resp. high), dealer 1's inventory position is close to (resp. away from) that of dealer 2, and dealers are less (resp. more) able to post competitive prices.

Note that, in our case, dealer 1, with the longer inventory position, has a decisive competitive advantage since the order flow $\left(Q_{D}+Q_{S}\right)$ is net-buying, whatever the sign of the component sent to the satellite market. She will thus try to trade the fraction of the order flow that best reduces her inventory exposure, i.e. $Q_{D}$. When her inventory position is more extreme $\left(I_{1}-I_{2}>Q_{D}\right)$, dealer 1 would rather execute at least the largest portion of the fragmented order flow (i.e., $Q_{D}$ ). When the divergence between dealers' inventories is low $\left(I_{1}-I_{2}<Q_{D}\right)$, she would prefer to trade at most $Q_{D}$. To clarify ideas, suppose that her inventory position is more extreme. If $Q_{S}>0$, then dealer 1 would prefer to execute the total order flow in market $D$ and $S$ to benefit from the cumulative effect, while if $Q_{S}<0$, she would prefer to trade only $Q_{D}$, and not $Q_{S}$, to avoid the offsetting effect. Conversely when the divergence of inventories is low, she prefers to avoid the cumulative effect if $Q_{S}>0$, but would like to profit from the offsetting effect if $Q_{S}<0$.

\footnotetext{
${ }^{8}$ Generalizing the definition of substitute goods to the case of nonidentical objects as in Krishna (2010) [Chapter 16, section 16.3 page 230], we will say that the objects being sold or bought are substitutes if the marginal value of obtaining (resp. selling) a particular object q is smaller if the set of objects already in hand (resp. sold) is "larger". Formally, dealer $i$ considers that $Q_{D}$ and $Q_{S}$ are substitutes if and only if $v_{i}\left(Q_{D}+Q_{S}\right)-v_{i}\left(Q_{S}\right) \leq v_{i}\left(Q_{D}\right)-v_{i}(0)$. For $Q_{D}>0$, the inequality holds if and only if $Q_{S}>0$.
} 
Finally, note that the characteristics of an equilibrium, if it exists, correspond to those of the outcome of the Vickrey-Clarke-Groves (VCG) mechanism for combinatorial auctions. ${ }^{9,10}$

The sign of the order flow sent to market $S$ influences dealers' preferences to trade (for $Q_{D}>0$ by assumption). We thus analyze separately the cases where $Q_{S}>0$ or $Q_{S}<0$ below.

\subsection{Order flows have the same sign}

In this section we suppose that the order flows routed to both the dominant and the satellite markets are net-buying, i.e. $Q_{D}>0$ and $Q_{S}>0$. Intuitively, dealer 1 with the longer inventory is in a position to be the first seller in market $D$ or $S$ (Ho and Stoll, 1983). Due to quote discrimination in multiple markets, dealer 2 has however the opportunity to post aggressive quotes only in one market. Dealer 1 thus faces a stronger competition which induces her to post very aggressive ask prices in both markets if she wants to trade the total fragmented order flow. Depending on her inventory holding costs, it may not be profitable to post such prices.

Proposition 1 Assume $Q_{S}>0$. If $I_{1}-I_{2}>Q_{D}$, there exists a unique Nash equilibrium, in which the longer dealer is the first seller in both markets. At equilibrium,

$$
\begin{aligned}
& \left(a_{+H}^{D}\right)^{*}=r_{2}\left(Q_{D}\right)-\varepsilon \\
& \left(a_{+H}^{S}\right)^{*}=r_{2}\left(Q_{S}\right)-\varepsilon .
\end{aligned}
$$

If $I_{1}-I_{2}<Q_{D}$, there exists a unique Nash equilibrium, in which the longer dealer is the first seller in the dominant market while the shorter dealer is the first seller in the

\footnotetext{
${ }^{9}$ In these auctions, multiple items, which are related but not necessarily identical, are sold simultaneously and bidders may submit bids on packages of items. Depending on the relative values bidders assign to the individual objects or to the bundle, sharing may be efficient.

${ }^{10}$ To illustrate the VCG mechanism, suppose that there are two items for sale $(D$ and $S)$ and two bidders. Let us denote by $v_{i}(D)$ bidder $i$ 's value for item $D$, by $v_{i}(S)$ bidder $i$ 's value for item $S$, and by $v_{i}(D S)$ bidder $i$ 's value for the bundle $D$ and $S$. In this mechanism, if $v_{1}(D S)>v_{1}(D)+v_{2}(S)$, then the outcome is that bidder 1 wins both items. This condition corresponds to our condition $\left(I_{1}-I_{2}-Q_{D}\right) Q_{S}>$ 0. See Vickrey (1961), Clarke (1971) and Groves (1973) or Ausubel and Milgrom (2006) for a discussion of the VCG mechanism.
} 
satellite market. At equilibrium,

$$
\begin{aligned}
& \left(a_{+L}^{D}\right)^{*}=r_{2}\left(Q_{D}\right)+\rho \sigma^{2} Q_{S}\left(\frac{Q_{D}-\left(I_{1}-I_{2}\right)}{Q_{D}}\right)-\varepsilon, \\
& \left(a_{+L}^{S}\right)^{*}=r_{1}\left(Q_{S}\right)+\rho \sigma^{2} Q_{D}-\varepsilon,
\end{aligned}
$$

where $\varepsilon$ corresponds to one tick.

The best quotes in markets $D$ and $S$ are continuous at $I_{1}-I_{2}=Q_{D}$, although the characteristics of the equilibrium (consolidation versus sharing) depend on the sign of $\left(I_{1}-I_{2}-Q_{D}\right)$ (Lemma 1). On the one hand, when the divergence between dealers' inventory positions is high, namely $I_{1}-I_{2}>Q_{D}$, the equilibrium is characterized by the consolidation of the order flow. The threat of being undercut by dealer 2 in each market induces dealer 1 to set aggressive prices. Observe indeed that, relative to Ho and Stoll (1983), the best ask prices in both markets $D$ and $S$ contain a new term with a negative sign: $\left(a_{+H}^{D}\right)^{*}=a^{H S}-\frac{\rho \sigma^{2}}{2} Q_{S}-\varepsilon$ and $\left(a_{+H}^{S}\right)^{*}=a^{H S}-\frac{\rho \sigma^{2}}{2} Q_{D}-\varepsilon$.

On the other hand, when the divergence is low $\left(I_{1}-I_{2}<Q_{D}\right)$, dealers share the fragmented order flow. The inventory position of dealer 1 is not any more extreme relative to dealer 2's inventory position, thus she cannot post sufficiently competitive prices to execute the total order flow. Consider the best ask in market $D$ posted by dealer 1 . This price is equal to the Ho and Stoll price plus a new term denoted $\omega:\left(a_{+L}^{D}\right)^{*}=a^{H S}+\omega Q_{S}$ where

$$
\omega=\frac{\rho \sigma^{2}}{2}\left(\frac{Q_{D}-2\left(I_{1}-I_{2}\right)}{Q_{D}}\right)
$$

This term $\omega$ is decreasing with the divergence in dealers' inventory. When dealers' inventories are very close $\left(I_{1}-I_{2} \rightarrow 0\right)$, they cannot post very different prices from each other, and competition is weak $(\omega>0)$. When dealers' inventories are more divergent $\left(I_{1}-I_{2} \rightarrow Q_{D}\right)$, dealer 1 is able to post more competitive quotes $(\omega<0)$. A similar reasoning holds for the best ask in market $S:\left(a_{+L}^{S}\right)^{*}=a^{H S}+\omega Q_{D}$. Note that dealers obtain a better allocation of risk compared to the Ho and Stoll benchmark in which dealer 1 is forced to execute the total order flow which leads her to a worse risk exposure. This better allocation of risks does not however necessarily lead to more competitive prices because dealers have less incentives to undercut each other by posting more aggressive prices. Sharing might thus allow dealers to post higher prices. This result is similar to 
that obtained in Biais, Foucault, Salanié (1998).

\subsection{Order flows have opposite signs}

This section analyzes the case where the order flow sent to market $D$ is net-buying $Q_{D}>0$, while the order flow sent to market $S$ is net-selling $Q_{S}<0$. Dealers must choose an ask price in market $D$, while they quote a bid price in market $S$. According to Ho and Stoll (1983) dealer 1 should be the first seller in market $D$, while dealer 2 is expected to be the first buyer in market $S$. However, the dealer who would simultaneously be the first seller and the first buyer would benefit from an "offsetting effect", i.e. the execution of the total order flow has a smaller inventory impact than the execution of only $Q_{D}$ or only $Q_{S}$.

Proposition 2 Assume that $Q_{S}<0$. If $I_{1}-I_{2}>Q_{D}$, there exists a unique Nash equilibrium, in which the longer dealer is the first seller in market $D$ and the shorter dealer is the first buyer in market $S$. At equilibrium,

$$
\begin{aligned}
& \left(a_{-H}^{D}\right)^{*}=r_{2}\left(Q_{D}\right)-\rho \sigma^{2}\left(-Q_{S}\right)-\varepsilon \\
& \left(b_{-H}^{S}\right)^{*}=r_{1}\left(Q_{S}\right)+\rho \sigma^{2} Q_{D}+\varepsilon,
\end{aligned}
$$

If $I_{1}-I_{2}<Q_{D}$, there exists a continuum of Nash equilibria in which the longer dealer is simultaneously the first seller in market $D$ and the first buyer in market $S$. All equilibria are such that $\left(a_{-L}^{D}\right)^{*} Q_{D}-\left(b_{-L}^{S}\right)^{*}\left(-Q_{S}\right)=r_{2}\left(Q_{D}+Q_{S}\right)\left(Q_{D}+Q_{S}\right)$. Among those equilibria, we focus on the equilibrium where prices in markets $D$ and $S$ are continuous when $I_{1}-I_{2} \rightarrow Q_{D}$.

$$
\begin{aligned}
& \left(a_{-L}^{D}\right)^{*}=r_{2}\left(Q_{D}\right)-\rho \sigma^{2}\left(-Q_{S}\right)-\varepsilon, \\
& \left(b_{-L}^{S}\right)^{*}=r_{2}\left(Q_{S}\right)+\varepsilon .
\end{aligned}
$$

where $\varepsilon$ corresponds to one tick.

When $I_{1}-I_{2}<Q_{D}$, we select the equilibrium on the criteria of price continuity at $I_{1}-I_{2}=Q_{D}$. Other equilibria exist, in which a higher bid price in market $S$ is compensated by a lower ask price in market $D$, but dealers' profits and the average half- 
spread paid by investors are not impacted by this choice: the average price at which $\left(Q_{D}+Q_{S}\right)$ is executed is $r_{2}\left(Q_{D}+Q_{S}\right)$.

When the divergence between dealers' inventory positions is high $\left(I_{1}-I_{2}>Q_{D}\right)$, the equilibrium is characterized by the sharing of the fragmented order flow. Competition might however be intense in equilibrium because $Q_{D}$ and $Q_{S}$ offset each other (they are acting as complement). Each dealer would like to trade only the fraction of the order flow which would best decrease their inventory exposure. In particular, the longer dealer, dealer 1 , is reluctant to add more inventory by trading the sell order $Q_{S}$, and posts therefore an aggressive ask price in market $D$ to attract the buy order $Q_{D}$. The best ask in market $D$ is lower than that in a consolidated market: $\left(a_{-L}^{D}\right)^{*}=a^{H S}-\frac{\rho \sigma^{2}}{2}\left(-Q_{S}\right)-\varepsilon$. An opposite situation holds in market $S$ in which dealer 2 can post non-competitive prices due to dealer 1' reluctance to trade the sell order sent to this market: $\left(b_{-H}^{S}\right)^{*}=a^{H S}+\omega Q_{D}$ where $\omega$, defined above in Eq. (3), is negative $(\omega<0)$. Sell orders in market $S$ are thus executed at a worse (smaller) price than in the benchmark in which they are batched with the net-buying portion $Q_{D}$ and transacted at $a^{H S}$.

When the divergence between dealers' inventory positions is low $\left(I_{1}-I_{2}<Q_{D}\right)$, dealer 1 would like to take advantage of the offsetting effect and trade profitably both components of the total fragmented order flow. However, the closer her inventory position is to her opponent's position, the less she is able to post competitive quotes: the equilibrium bid quote in market $S$ rewrites $\left(b_{-L}^{S}\right)^{*}=r_{1}\left(Q_{S}\right)+\rho \sigma^{2}\left(I_{1}-I_{2}\right)+\varepsilon$, which tends to $r_{1}\left(Q_{S}\right)+\varepsilon$ when $I_{1}-I_{2} \rightarrow 0$, but to a higher limit price $\left(r_{1}\left(Q_{S}\right)+\rho \sigma^{2} Q_{D}+\varepsilon\right)$ when $I_{1}-I_{2} \rightarrow Q_{D}$. Therefore two opposite forces coexist which yields to a more competitive price in market $D$ and a less competitive price in market $S$, compared to the benchmark: $\left(a_{-L}^{D}\right)^{*}=a^{H S}-\frac{\rho \sigma^{2}}{2}\left(-Q_{S}\right)-\varepsilon$, and $\left(b_{-L}^{S}\right)^{*}=a^{H S}-\frac{\rho \sigma^{2}}{2} Q_{D}-\varepsilon$.

\subsection{Empirical predictions}

This section investigates the impact of strategic quoting behaviors of dealers across venues on the market performance. This enables us to propose some new testable implications. 


\subsubsection{Expected best offers}

In our model, the price of the same asset may differ across venues for two reasons. First, the size of the order flow routed to each venue is different, implying a different price impact when executed. Second, dealers manage their position globally, i.e. across two venues. Therefore dealers place quotes in one venue taking into account the potential impact of trading in the other venue. Dealers' quoting aggressiveness depends on their eagerness to share or consolidate the total fragmented order flow given their global inventory position. The inter-dependant quoting aggressiveness across venues in turn impacts the magnitude of market spreads in each venue (see Proposition 3 below).

Following Propositions 1 and 2 which define optimal quotes when the longer dealer is dealer 1 and $Q_{D}>0$, Proposition 3 below analyzes the expected best offers in the dominant and satellite markets for any set of inventory positions and any order flow $Q_{D}$. For ease of exposition, we denote by $q_{m}$ the magnitude of the order flow routed to market $m: q_{m}=-Q_{m}$ for a net-selling order flow and $q_{m}=Q_{m}$ for a net-buying order flow $(m=D, S)$.

Proposition 3 Under the assumption that $q_{D}<\left(I_{u}-I_{d}\right)$, the expected best offers in the dominant and the satellite markets respectively write:

$$
\begin{gathered}
E\left(\underline{a}^{D}\right)=\frac{2 r_{d}\left(q_{D}\right)+r_{u}\left(q_{D}\right)}{3}+\lambda_{S} \rho \sigma^{2} q_{S}\left[\gamma\left(\frac{\rho \sigma^{2} q_{D}}{\left(r_{d}-r_{u}\right)}-\frac{\left(\rho \sigma^{2} q_{D}\right)^{2}}{3\left(r_{d}-r_{u}\right)^{2}}\right)-(1-\gamma)\right], \\
E\left(\underline{a}^{S}\right)=\frac{2 r_{d}\left(q_{S}\right)+r_{u}\left(q_{S}\right)}{3}+\lambda_{D} \rho \sigma^{2} q_{D}\left[\frac{\rho \sigma^{2} q_{D}}{\left(r_{d}-r_{u}\right)}-\frac{\left(\rho \sigma^{2} q_{D}\right)^{2}}{3\left(r_{d}-r_{u}\right)^{2}}-(1-\gamma)\right]
\end{gathered}
$$

In line with the intuitions exposed above, the first component of the expected best offer (equations (4) and (5)) is the direct price impact of the order flow routed to this venue. It corresponds to the expected best offer that would prevail if $q_{-m}$ is zero (or $\lambda_{-m}=$ $0)$. The second component consists of the indirect price impact of trading in another venue $\left(q_{-m}\right)$ resulting from the interdependent quoting strategies of global market-making. Consequently, when non-zero order flows arrive simultaneously (with probability $\lambda_{-m}>0$, $m=S, D)$, the average best prices in one venue depend on the size $\left(q_{-m}\right)$ and the sign 
of the order flow routed to the alternative trading venue $(\gamma)$. The next corollary explores these relations.

Corollary 1 Expected best offers are impacted by the probability to observe order flows of same signs across venues $(\gamma)$ and by the size of the order flows routed to other venues $\left(q_{-m}\right)$. In particular, if order flows are simultaneously non-zero $\left(\lambda_{-m}>0\right)$, then

(1) the expected best offer in each venue increases with $\gamma$;

(2) the expected best offer in market $D$ decreases with $q_{S}$ if $q_{D}<q_{D}^{*}(\gamma)$, while the expected best offer in market $S$ decreases with $q_{D}$ if $q_{D}<q_{D}^{* *}(\gamma)$.

Intuitively, when $\gamma$ is large, the likelihood of facing a cumulative effect due to the execution of trades of same signs is high. An increase in $\gamma$ thus leads to an increase in best asks prices reflecting the increasing cost of providing immediacy by dealers.

The effect of the size of the alternative order flow $\left(q_{-m}\right)$ is however less clear-cut, since it depends on its sign (via $\gamma$ ). If $q_{-m}$ is large, the indirect price impact is large. The sign of the price impact depends however on $\gamma$. For small values of $\gamma$, best offers may benefit from an offsetting effect. Conversely, when $\gamma$ is large, best offers incorporate the costly impact of a cumulative effect. Consider the limit cases. When $\gamma=0$, the larger is the indirect price impact of the offsetting effect, the lower best offers can be: best offers always decrease with $q_{-m}$. In contrast, if $\gamma=1$, the indirect price impact of the cumulative effect is large, and average prices worsen (expected best offers increase with $\left.q_{-m}\right)$. For any value of $\gamma$ except 0 and 1, best offers depend on the interplay between the size and the sign of the order flow routed to the other venue. They also depend on dealers' quoting aggressiveness resulting from the probability to consolidate or not the total fragmented order flow, which explains the conditions obtained on $q_{D}$.

Note that this corollary enables us to develop new empirical predictions that we test in the next section. Before turning to testing implications of the model, one natural question ensuing from the previous corollary is about market performance: best offers vary with trading in the other venue, but overall, is market performance better or worse when liquidity supply strategically splits across venues?

From Proposition 3, we can calculate the total expected execution costs in order to determine whether making the market across multiple venues has a positive or negative impact on investors. The next corollary compares them to expected transaction costs 
that would prevail in a consolidated market (our natural benchmark).

Corollary 2 Expected transaction costs are lower in fragmented markets than in a consolidated market if $\gamma>\frac{1}{3}$ and $q_{D}$ is neither too large, nor too small $\left(r_{\gamma}^{1}\left(I_{u}-I_{d}\right)<q_{D}<\right.$ $\left.r_{\gamma}^{2}\left(I_{u}-I_{d}\right)\right)$

Intuitively, Corollary 2 results from comparing dealers' quoting aggressiveness when they are able to split liquidity across trading venues or not (for the same $Q_{D}+Q_{S}$ ). Recall that the competitiveness of dealers' quoting strategies depends on the divergence between dealers' inventory positions. The intuition is as follows: for large values of $\gamma$, if $q_{D}$ is large, the probability that dealers' inventory are highly divergent is low, which in turn implies that the probability to observe more aggressive quoting strategies than in the benchmark is also low (see previous section). Expected transaction costs are thus higher in case of fragmented trading. When $q_{D}$ is small enough, dealers' prices are more likely to be more competitive, and even more competitive than the benchmark, leading to lower average transaction costs. For small values of $\gamma$, if $q_{D}$ is small, a small divergence between dealers' inventory position is less likely, and the probability to observe quoting strategies as aggressive as in the benchmark is small. If $q_{D}$ is large, this probability is higher. The higher competitiveness of dealers' quotes is thus obtained in two opposite situations: for large $q_{D}$ when $\gamma$ is small and for small $q_{D}$ when $\gamma$ is large. The second situation has on average a larger impact, resulting in more competitive spreads when $q_{D}$ is small enough but not too small (depending on $\gamma$ ).

This ambiguous result of fragmentation on market performance is consistent with the mixed empirical evidence as to whether market quality is higher in a fragmented or in a consolidated market (see the literature review section of O'Hara and Ye, 2011). In our model, global market-makers consolidate the order flow through their inventory management, which may have a positive externality in some cases. Few theoretical models find some positive impacts of fragmentation of trading. Foucault and Menveld (2008) show that the consolidated depth is larger due to the presence of investors who consolidate the market through their order submission. 


\section{Empirical analysis}

Our model predicts that spreads in one venue market depend on the characteristics of order flow routed to the alternative venue. To test these predictions, we use a proprietary dataset from Euronext.

\subsection{Forming the sample}

Euronext was created in 2000 as a result of the merger of three European exchanges, namely Amsterdam, Brussels and Paris. Lisbon joined in 2002. Before the introduction of the Universal Trading Platform (UTP) in 2009, the four exchanges maintained their domestic market. As a result, firms could be multi-listed on several Euronext exchanges; for example, Air France-KLM was traded in Amsterdam and in Paris.

Our sample consists of all cross-listed stocks within Euronext, spanning four months (79 trading days) from January 1, 2007 to April 30, 2007.11 The data on trades and quotes are provided by Euronext. Euronext files also provide us with the identification of the member participating in each quote or transaction, and whether the member is acting as an agent or as a principal. The data assigns the same code to a member across stocks and across exchanges, enabling us to trace members' inventory changes and quoting behavior across time and across exchanges. Euronext exchanges follow the same market model (same trading hours, and same trading rules), and the payment of membership fees grants access to all Euronext markets. Note also that, during our sample period (pre-MiFID environment), trading was concentrated in Euronext. ${ }^{12}$ For all these reasons, Euronext is an excellent environment to test the predictions of our model.

We keep firms that trade using a continuous trading session in all exchanges on which they are traded. We also restrict our analysis to members acting in their capacity as a principal, that is, either proprietary traders or exchange-regulated market makers, who trade at least once every month in each of the two exchanges on which the stock is traded. Overall, we follow 42 members, denominated as 'global dealers'. Because these dealers do

\footnotetext{
${ }^{11}$ Three trading days are dropped in January due to missing data about best limits.

${ }^{12}$ Some French stocks were traded on the LSE or the Deutsche Boerse, while some Dutch stocks were traded in Xetra. Gresse, 2012 finds a market share of $96.45 \%$ for CAC40 stocks and even $99.99 \%$ for other SBF120 stocks in October 2007. Degryse, De Jong, and van Kervel, 2011, show that Euronext concentrates the trading volume of the 52 AEX Large and Mid cap constituents on our sample period.
} 
not necessarily follow the same stocks, our sample finally consists of 156 couples (stock, dealer).

We also collect information on prices (closing, high and low), shares outstanding and trading volume from COMPUSTAT Global over our sample period. The final sample contains 20 firms with non-missing data, trading continuously in two Euronext exchanges. Among them, 11 are traded on Euronext Amsterdam, 12 are traded on Euronext Brussels and 17 on Euronext Paris. To determine which is the dominant market (market $D$ in the model) and which is the satellite market (market $S$ in the model), we sort markets for each stock according to the trading volume in number of shares as of December 31, 2006. As documented by Figure 2, there is a clear hierarchy of the markets, making straightforward the identification of the dominant market (see also summary statitics presented in Table 1).

\subsubsection{Measuring liquidity}

We measure the spread in the market $m$ as the daily equally-weighted average bid-ask spread for stock $j$, on day $t$. We focus on two measures, the relative spread $R S P R E A D \_m$, and the spread in Euros, SPREAD_m. ${ }^{13}$

\subsubsection{Measuring global inventory}

As pointed out by Hansch et al. (1998), dealers differ in the amount of capital at risk they commit to their trading activities and/or in their risk aversion. We follow their methodology by building standardized inventory positions to control for these differences. Let $I P_{i, t}^{j}$ denote the inventory position of member $i$ in stock $j$ at the end of day $t$. We use the record of all trades executed by each member in multiple markets as a principal, plus the direction of these trades in both markets to obtain her inventory position at the end of each day. We thus construct a time series for each member's inventory position in each stock from the start to the end of our sample period. Since more than $95 \%$ of the volumes are traded in Euronext during our sample period, our inventory variable is a good proxy for dealers' global inventories. We compute the mean $\left(\overline{I P}_{i}^{j}\right)$ and the standard

\footnotetext{
${ }^{13}$ We compute both equally-weighted and time-weighted averages of the quoted spreads. As the results for the two weighting schemes are virtually identical, we restrict the presentation to the equally-weighted spread measures.
} 
deviation $\left(S_{i}^{j}\right)$ for each of these inventory series. The standardized inventory is defined as follows:

$$
I_{i, t}^{j}=\frac{I P_{i, t}^{j}-\overline{I P}_{i}^{j}}{S_{i}^{j}} .
$$

There is a total of 156 standardized inventory series.

We then build a measure of the relative inventory. Let $I_{M, t}^{j}$ denote the median inventory on day $t$ in stock $j$, and let $R I_{i, t}=I_{i, t}^{j}-I_{M, t}^{j}$ denote the member $i$ 's inventory position relative to the median inventory. The larger $R I_{i}$, the more divergent the inventory position of member $i$ relative to the median is, and the more aggressively she will quote, in order to reduce her inventory exposure (Hansh et al., 1998). We take the standard deviation of the relative inventory across members for each day $t$ and each stock $j, S R I_{t}^{j}$, to get the degree of quoting aggressiveness induced by inventory management. We use this measure as a proxy of the difference $I_{1}-I_{2}$ in our model.

\subsubsection{Measuring net order flow}

Following Chordia and Subrahmanyam, 2004 and Boehmer and $\mathrm{Wu}, 2008$, we define the absolute net order flow in market $m$ (i.e., order imbalance) in stock $j$ on day $t, O I M B \_m$, as the daily number of buyer-initiated trades $\left(N B \_B U Y \_m\right)$ minus the daily number of seller-initiated trades $\left(N B \_S E L L \_m\right)$ scaled by the daily total number of trades (to eliminate the impact of total trading activity) as follows:

$$
O I M B \_m_{t}^{j}=\frac{\left|N B \_B U Y \_m_{t}^{j}-N B \_S E L L \_m_{t}^{j}\right|}{N B \_B U Y \_m_{t}^{j}+N B \_S E L L \_m_{t}^{j}}
$$

We exclude the first and last five minutes of trading in order to avoid contamination by specific trading behaviors during the open or close of the markets. ${ }^{14}$ As a robustness check we also use measures of order imbalance in Euros in some of our tests.

In addition, the model's predictions depend on the sign of the order flow sent to a given market. We therefore calculate the twenty-minute order imbalance within each market (the satellite and the dominant market) and compute the daily correlation between these order imbalances. The dummy variable $D_{-} P O S\left(D_{-} N E G\right)$ takes the value of one if the

\footnotetext{
${ }^{14}$ In February 19, 2007, the closing fixing moved from 5:25 pm to 5:30 pm. We therefore drop all observations before 9:05 am and after 5:20 pm.
} 
correlation is positive (negative) on a given day, and zero otherwise.

\subsubsection{Control variables}

In the regressions, we use the monthly averages of the following stock control variables observed in the previous month: $M V$, the log market capitalization in millions of Euros; HIGHLOW, a measure of volatility computed using the range of high and low prices in the day, following Parkinson (1980); VOLSHR, the log daily volume in millions of shares; and when using order imbalances in Euros as variables of interest, the inverse of the price, 1/PRICE, where PRICE refers to the closing price in Euros. We further introduce $N B R_{-} D E A L E R S$, the number of global dealers, to control for the degree of competitiveness in the stock.

\subsection{Summary statistics}

Table 1 presents summary statistics for our sample. Panel A presents statistics across stocks. The average (median) firm has a stock price of 44.3 (36.9) Euros, a market cap of 32.7 (23.2) billion Euros, and 9 (4) members trading on the stock. Panel B presents statistics computed within each market. Relative (quoted) spreads of the satellite market are four to eight times larger than those of the dominant market, depending if one takes means or medians. Order imbalances are also much larger in the satellite market, reflecting price pressure due to lack of liquidity, and trading volume and trade activity much smaller. T-tests of the difference in means between the two markets (not shown) confirm the statistical significance of these differences.

\subsection{Multivariate analysis}

To test the predictions of our model, we estimate the relation between the daily spreads in the satellite market and the order flow sent to the dominant market. We run the following panel regression model:

$R S P R E A D_{-} S A T_{t}^{j}=\alpha+\beta_{1} O I M B_{-} D O M_{t}^{j}+\beta_{2} D_{-} P O S_{t}^{j}+\beta_{3} S R I_{t}^{j}+\beta_{4} O I M B_{-} S A T_{t}^{j}+\beta_{5} \mathbf{X}^{j}+\varepsilon_{t}^{j}$

The matrix $\mathbf{X}^{j}$ controls for characteristics of the stock $j$ using the control variables 
mentioned above $\left(N B_{-} D E A L E R S, M V, H I G H L O W\right.$, and $V O L S H R$, the latter three averaged for the previous calendar month).

Corollary 1 predicts that the size, and the sign of the order flow routed to the dominant market impact the spreads in the satellite market. More specifically, we expect the following signs: $\beta_{1}>0$, and $\beta_{2}>0$. Given that the standard deviation of the relative inventory across dealers, $S R I$, is a proxy for quoting aggressiveness, we expect $\beta_{3}<0$. Finally, the net order flow sent to the satellite market, OIMB_SAT, controls for the direct price impact of trades, we thus expect $\beta_{4}>0$.

All specifications include time dummies and use clustered standard errors by stock to accommodate the possibility that relative spreads are strongly correlated within firms.

Panel A of Table 2 presents estimation results (results for Panel B are similar and are not discussed for the sake of brevity). The overall fit of the model across the three specifications is good, with an adjusted $R^{2}$ statistic of $37 \%$. The main conclusions from the analysis are as follows. First, the order flow of the dominant market has a positive and statistically significant impact on the relative spreads of the satellite market (coeff. 1.51, t-stat. 2.77 in column 1). In terms of economic significance, a one-standard deviation shock in $O I M B_{-} D O M(0.201$ from Table 1$)$ is associated with a 0.3 change in $R S P R E A D \_S A T$, representing roughly $25 \%$ of the average relative spread in the satellite market. Surprisingly we find no statistical significant coefficient for the order flow sent to the satellite market on its own observed spreads. Second, the variable SRI has a negative and statistical significant impact on spreads (coeff. -0.42, t-stat. -1.93). Dealers post more aggressive prices when there is a high difference of inventories between them, as expected. Third, the satellite market exhibits lower relative spreads on days in which its order flow is positively correlated with that of the dominant market, also consistent with the model's predictions (coeff. 0.19, t-stat. 2.15).

Column 2 introduces an additional interaction variable between D_POS and SRI. Consistent with the model, we find that dealers post more aggressive prices in those cases relative to the unconditional case (coeff. -0.32, t-stat. 1.69). Finally, column 3 includes for completeness a specification with $D_{-} N E G$, the symmetric of $D_{-} P O S$. The results confirm the prediction symmetric of that discussed above, namely, that days in which order flow exhibits different signs in the two markets are associated with lower spreads in the satellite market. 
Regarding the other control variables, the existence of a higher number of members leads to more competition and reduces spreads (Biais, 1993), while trading volume is also associated with lower spreads. Results for other control variables are not statistically significant.

\section{Conclusion}

Markets are nowadays fragmented. Investors therefore have the opportunity to search for the best price and split their orders accordingly, but free entry in new trading venue also enables the same pool of liquidity suppliers to make different markets. To investigate the impact of fragmentation on the behavior of these liquidity suppliers, we develop an inventory model in which risk averse liquidity suppliers quote a single asset in multiple venues. We exploit the co-existence of multiple order books for the same security within Euronext to test the predictions of our simple model. Our panel regression analysis reveals that the size of the bid-ask spread in a venue is related:

- to the order flow routed to the alternative venue,

- to whether net order flows are positively or negatively correlated, and

- to the dispersion in liquidity suppliers' inventory positions.

These empirical findings are in line with the predictions of the model and are not easily explained by alternative theories. This has interesting implications as the latter usually show that fragmentation increases bid-ask spreads, while we find the opposite in some cases. The intuition of this result is that when liquidity suppliers are active in different venues, they actually consolidate the markets - therefore mitigating the negative effect of competition, while increasing no only inter-market competition on fees, but also intra-market competition between dealers.

There are several interesting venues for future research. On the empirical front, Euronext' move to a single order book with UTP in 2009 would provide a natural experiment to compare the overall liquidity in fragmented versus consolidated market.

On the theoretical front, it would be interesting to investigate whether fragmented markets are consolidated by market makers via alternative channels to inventory management, whether their private information, or their anticipation of adverse selection. 
Besides, Buti, Rindi, and Werner, 2011 find that increased dark pool activity improves market quality in the NYSE and in the Nasdaq. Our analysis raises intriguing questions about the co-existence of transparent venues and dark pools in the presence of global dealers, as our model relies on the transparency of order flows and prices.

\section{References}

[1] Baruch, Shmuel, Andrew Karolyi, and Michael Lemmon, 2007, "Multi-Market Trading and Liquidity: Theory and Evidence," Journal of Finance, 62, 2169-2200.

[2] Bernhardt, Dan, and Eric Hughson, 1997,"Splitting Orders," Review of Financial Studies, 10, 69-101.

[3] Biais, Bruno, 1993, "Price Information and Equilibrium Liquidity in Fragmented and Centralized Markets," Journal of Finance, 1, 157-185.

[4] Biais, Bruno, Lawrence Glosten, and Chester Spatt, 2005, "Market Microstructure: a Survey of Microfoundations, Empirical Results, and Policy Implications", Journal of Financial Markets, 8, 217-264.

[5] Blume, Marshall, and Michael Goldstein, 1997, "Quotes, Order Flow, and Price Discovery," Journal of Finance, 52, 221-244.

[6] Boehmer, Ekkehart, and Julie Wu, 2008, "Order flow and prices," working paper presented at AFA 2007 Chicago meetings

[7] Brogaard, Jonathan, 2011, "High frequency trading and its impact on market quality," mimeo.

[8] Buti, Sabrina, Barbara Rindi, and Ingrid Werner, 2011, "Diving into Dark Pools," working paper, Fisher College of Business.

[9] Chordia, Tarun, and Avanidhar Subrahmanyam, 2004, "Order Imbalance and Individual Stock Returns: Theory and Evidence," Journal of Financial Economics, 72, 485-518. 
[10] Chowdhry, Bhagwan. and Vikram Nanda, 1991, "Multimarket Trading and Market Liquidity," Review of Financial Studies, 4, 483-511.

[11] Degryse, Hans, Frank de Jong, and Vincent van Kervel, 2011, "The impact of dark trading and visible fragmentation on market quality," CEPR discussion paper 8630.

[12] Easley, David, Nicholas Kiefer, and Maureen O'Hara, 1996, "Cream-skimming or Profit-Sharing? The Curious Role of Purchased Order Flow," Journal of Finance, 51, 811-833.

[13] Foucault, Thierry, and Albert Menkveld, 2008, "Competition for Order Flow and Smart Order Routing Systems," Journal of Finance, 63, 119-158.

[14] Gresse, Carole, 2012, "Effects of Lit and Dark Trading Venue Competition on Liquidity: The MiFID Experience,"Working Paper 8, AMF Resarch Department.

[15] Halling, Michael, Pamela Moulton, and Marios Panayides, 2013, "Volume Dynamics and Multimarket Trading," forthcoming in Journal of Financial and Quantitative Analysis.

[16] Hoffman, Peter, "Adverse Selection, transaction fees, and multi-market trading," mimeo.

[17] Hansch, Oliver, 2004, "The Cross-Sectional Determinants of Inventory Control and the Subtle Effects of ADRs," Journal of Banking and Finance, 28, 1915-1933.

[18] Hansch, Oliver, Narayan Naik, and S. Viswanathan, 1998, "Do Inventories Matter in Dealership Markets? Evidence from the London Stock Exchange," Journal of Finance, 53, 1623 - 1656.

[19] Ho, Thomas, and Hans Stoll, 1983, "The dynamics of dealer markets under competition," Journal of Finance, 38, 1053-1074.

[20] Huang, Roger, 2002, "The Quality of ECN and Nasdaq Market Maker Quotes," Journal of Finance, 57, pp. 1285-1319.

[21] Jovanovic, Boyan, and Albert Menkveld, 2011, "Middlemen in Limit-Order Markets," working paper presented at the WFA 2011. 
[22] Krishna, Vijay, 2010, "Auction Theory," Academic Press, Elsevier Inc.

[23] Menkveld, Albert, 2008, "Splitting Orders in Overlapping Markets: A Study of CrossListed Stocks," Journal of Financial Intermediation, 17, 145-174.

[24] Menkveld, Albert, 2012, "High Frequency Trading and the New-Market Makers," mimeo.

[25] O'Hara, Maureen, and Mao Ye, 2010, "Is market fragmentation harming market quality," Journal of Financial Economics, 100, 459-474.

[26] Pagano Marco, 1989, "Trading Volume and Asset Liquidity," Quarterly Journal of Economics, 1989, 255-274.

[27] Parlour, Christine, and Duane Seppi, 2003, "Liquidity-Based Competition for Order Flow," Review of Financial Studies, 16, 301-343.

[28] Riordan, Ryan, Andreas Storkenmaier, and Martin Wagener, 2011, "Do Multilateral Trading Facilities Contribute to Market Quality?, "working paper, Karlsruhe Institute of Technology.

[29] Seppi, Duane, 1997, "Liquidity Provision with Limit Orders and a Strategic Specialist," Review of Financial Studies, 10, 103-150.

[30] van Kervel, Vincent, 2012, "Liquidity: What you see is what you get?," mimeo

[31] Ausubel, Lawrence, and Paul Milgrom, 2006, "The Lovely but Lonely Vickrey Auction," Chapter 1 in P. Cramton, Y. Shoham, and R. Steinberg (eds.), Combinatorial Auctions, MIT Press.

[32] Clarke, Edward, 1971, "Multipart Pricing of Public Goods," Public Choice, 11, 1733.

[33] Groves, Theodore, 1973, "Incentives in Teams,", Econometrica, 41, 617631.

[34] Vickrey, William,1961, "Counterspeculation, Auctions, and Competitive Sealed Tenders," Journal of Finance, 16, 837. 


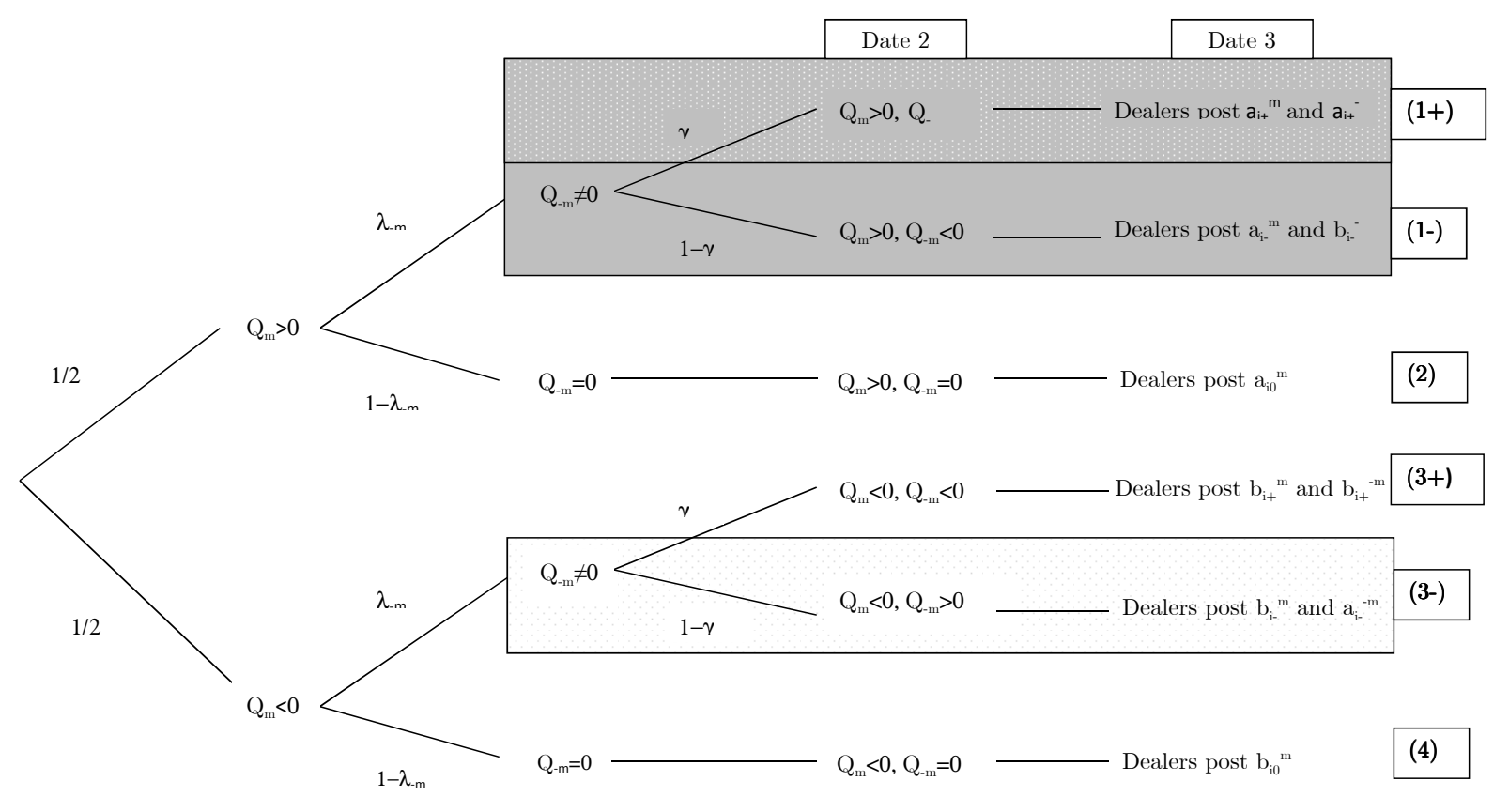

Figure 1: Quoting game in market $\mathrm{m}$ conditional on dealers observing $Q_{m} \neq 0$

Figure 1 represents the extensive form of the quoting game in market $m$, conditional on $Q_{m} \neq 0$. At date 2 , dealers observe $Q_{m} \neq 0$ and $Q_{-m}$. At date 3 , they post an ask price if $Q_{m}>0$ or a bid price if $Q_{m}<0$ in market $m$. Simultaneously, if $Q_{-m} \neq 0$, they post an ask price if $Q_{-m}>0$ or a bid price if $Q_{-m}<0$ in market $-m$. In Section 3, we find the equilibrium quotes of the subgames (1+) and (1-) for $m=D$, and (1+) and (3-) for $m=S$. 

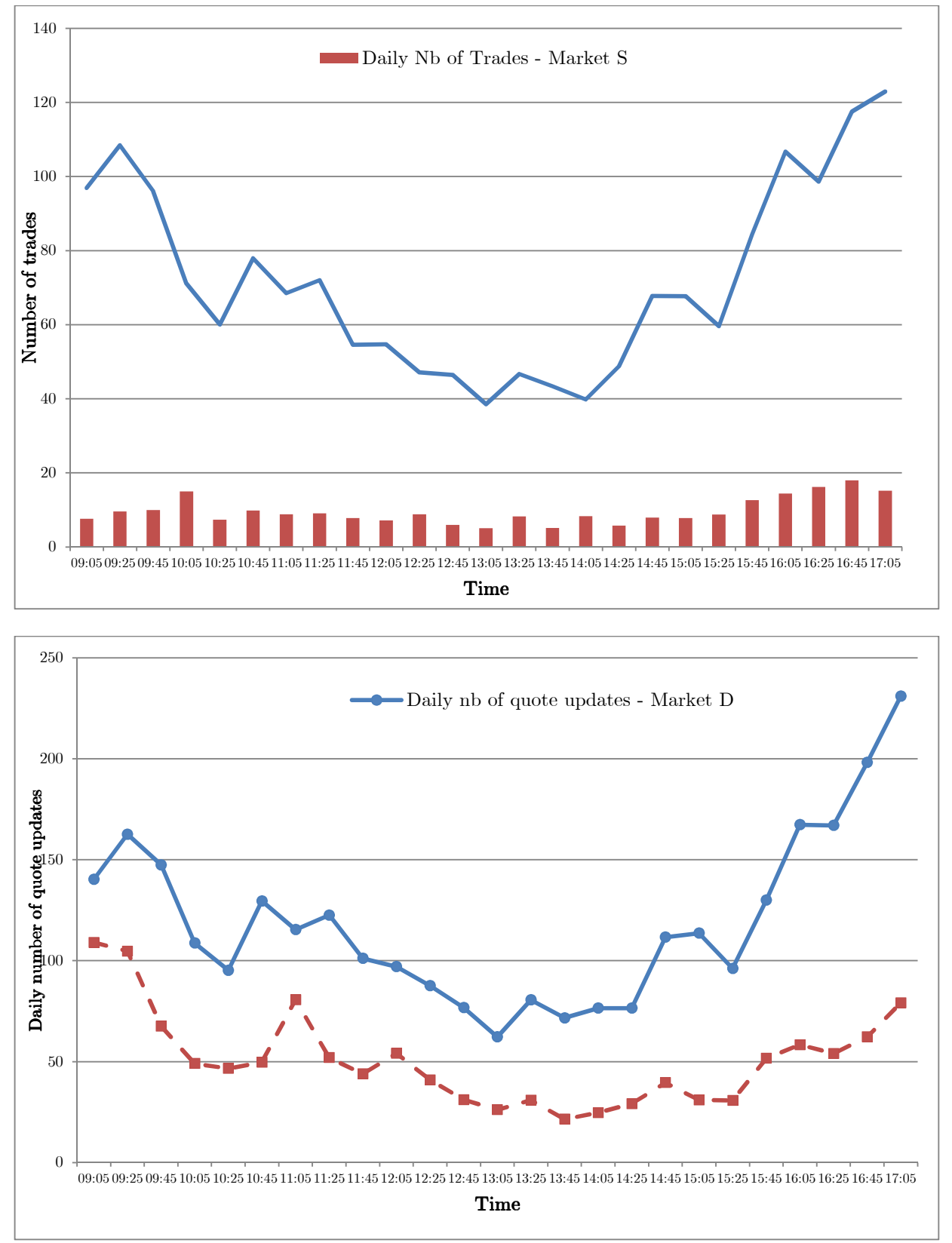

Figure 2: Daily number of trades and daily number of quote updates in the dominant and the satellite market

The average daily number of trades and number of quote updates for each 20-minute period from 9:05 am to 17:25 pm in each trading venue is calculated for each stock and then averaged across stocks for the 20 cross-listed Euronext stocks from January to April 2007. 
Table 1

\section{Summary statistics}

This table reports summary statistics for the data used in this study. The sample consists of 20 multi-listed, continuously-traded stocks on Euronext exchanges, from January 1, 2007 through April 30, 2007 (79 trading days). The quotes and trades data come from Euronext, and other stock-level information comes from Compustat Global. Panel A reports stock-level statistics. PRICE is the daily closing price in Euros from Compustat Global. HIGHLOW is a measure of volatility computed using the range of high and low prices for the day, following Parkinson (1980). Market capitalization (MV) is price times shares outstanding, in millions of Euros. SRI is the dispersion of the members' inventory relative to the median inventory position, measured in number of shares. SRI_EUR is calculated similarly, but is measured in Euros. NBR_DEALERS is the number of dealers acting as a principal and trading at least once every month. Panel B reports summary statistics by market type. SPREAD is the equally-weighted average difference between the best bid and the best ask. MIDPOINT is the average, throughout the trading day, of the average between the best bid and the best ask. RSPREAD, or relative spread, is equal to the equally-weighted average of ratio between the spread and the midpoint. VOLSHR is the daily volume reported in millions of shares. NBR_TRAN is the number of trades per day. OIMB is a measure of absolute order imbalance in number of transactions, computed as the absolute value of the average of the daily number of buyer-initiated trades less the daily number of seller-initiated trades for the entire trading day, scaled by daily volume. 
Table 1

Summary statistics (cont.)

\begin{tabular}{lcrrrrr}
\hline \multicolumn{7}{c}{ Panel A. Summary statistics } \\
\hline & $\mathrm{N}$ & \multicolumn{1}{c}{ Mean } & Std. Dev. & \multicolumn{1}{c}{ Q1 } & Median & Q3 \\
\hline PRICE & 1307 & 44.329 & 30.199 & 21.370 & 36.900 & 53.950 \\
HIGHLOW & 1307 & 0.094 & 0.146 & 0.029 & 0.055 & 0.105 \\
MV & 1307 & 32745.340 & 34476.740 & 8835.779 & 23278.160 & 51339.430 \\
SRI & 1307 & 0.268 & 0.411 & 0.013 & 0.063 & 0.323 \\
SRI_EUR & 1307 & 9.970 & 19.468 & 0.431 & 2.681 & 10.192 \\
NBR_DEALERS & 1307 & 8.972 & 8.660 & 3 & 4 & 12 \\
& & & & & & \\
\hline
\end{tabular}

Panel B. Summary statistics by market type

\begin{tabular}{|c|c|c|c|c|c|c|}
\hline & \multicolumn{6}{|c|}{ Dominant market } \\
\hline & $\mathrm{N}$ & Mean & Std. Dev. & Q1 & Median & Q3 \\
\hline SPREAD & 1307 & 0.088 & 0.110 & 0.019 & 0.042 & 0.121 \\
\hline MIDPOINT & 1307 & 45.055 & 30.143 & 21.317 & 38.137 & 54.358 \\
\hline RSPREAD & 1307 & 0.271 & 0.386 & 0.065 & 0.106 & 0.251 \\
\hline VOLSHR & 1307 & 4.514 & 8.835 & 0.062 & 1.109 & 6.105 \\
\hline NBR_TRAN & 1307 & 3941.944 & 4425.691 & 169 & 2598 & 6247 \\
\hline \multirow[t]{3}{*}{ OIMB } & 1307 & 0.195 & 0.201 & 0.056 & 0.116 & 0.261 \\
\hline & \multicolumn{6}{|c|}{ Satellite market } \\
\hline & $\mathrm{N}$ & Mean & Std. Dev. & Q1 & Median & Q3 \\
\hline SPREAD & 1307 & 0.651 & 0.954 & 0.060 & 0.159 & 1.114 \\
\hline MIDPOINT & 1307 & 45.002 & 30.062 & 21.318 & 38.132 & 54.098 \\
\hline RSPREAD & 1307 & 1.202 & 1.365 & 0.201 & 0.831 & 1.554 \\
\hline VOLSHR & 1307 & 0.131 & 0.570 & 0.000 & 0.003 & 0.015 \\
\hline NBR_TRAN & 1307 & 152.334 & 538.174 & 2.000 & 12.000 & 47.000 \\
\hline OIMB & 1307 & 0.427 & 0.366 & 0.086 & 0.335 & 0.754 \\
\hline
\end{tabular}




\section{Table 2}

\section{Determinants of Relative Spreads in the Satellite Market}

This table presents estimates of the relation between order imbalances for the trading day and relative bidask spreads in the satellite market, conditional on stock characteristics. The left-hand side variable is RSPREAD_SAT, the equally-weighted daily average of ratio between the difference between the best bid and the best ask (the spread) and the average between the best bid and the best ask (the midpoint) in the satellite market. The right-hand-side variable of interest is OIMB_DOM (OIMB_DOM_EUR), the absolute value of the average of ratio between the daily number (value) of buyer-initiated shares less the daily number (value) of seller-initiated shares and the total volume in shared for the entire trading day in the dominant market. OIMB_SAT (OIMB_SAT_EUR) is calculated similarly for the satellite market. SRI (SRI_EUR) is the dispersion of the members' inventory relative to the median inventory position, measured in number of shares (Euros). D_POS (D_POS_EUR) is an indicator variable that takes the value of 1 if the intra-day correlation of the 20-minute order imbalance measured using the number (value) of trades between the dominant and the satellite market is positive, and zero otherwise. D_NEG (D_NEG_EUR) is an indicator variable that takes the value of 1 if the intra-day correlation of the 20-minute order imbalance measured using the number (value) of trades between the dominant and the satellite market is negative, and zero otherwise. NBR_DEALERS is the daily number of liquidity suppliers acting as a principal and trading at least once every month. MV is the (log of) market capitalization. HIGHLOW is a measure of volatility computed using the range of high and low prices for the day, following Parkinson (1980). VOLSHR is the ( $\log$ of) daily volume reported in millions of shares. 1/PRICE is the inverse of the daily closing price in Euros. The variables MV, HIGHLOW, VOLSHR and 1/PRICE used in this regression are the monthly averages of daily values observed in the previous month. Panel A shows specifications using variables with order imbalances and inventory measured in number of shares and Panel B shows specifications using variables with order imbalances and inventory measured in Euros. The model includes time dummies and tstatistics are calculated using robust standard errors clustered by stock. The symbols $* * *, * *, *$ denote significance levels of $1 \%, 5 \%$ and $10 \%$, respectively. for the two-tailed hypothesis test that the coefficient equals zero. 
Table 2

Determinants of Relative Spreads in the Satellite Market (cont.)

\begin{tabular}{|c|c|c|c|c|c|c|c|c|c|}
\hline \multicolumn{10}{|c|}{ Panel A. } \\
\hline \multirow[t]{3}{*}{ Dependent variable: } & \multicolumn{9}{|c|}{ RSPREAD_SAT } \\
\hline & \multicolumn{3}{|c|}{$(1)$} & \multicolumn{2}{|c|}{$(2)$} & \multicolumn{4}{|c|}{$(3)$} \\
\hline & Coeff. & t-stat. & & Coeff. & t-stat. & & Coeff. & t-stat. & \\
\hline OIMB_DOM & 1.51 & 2.77 & $* *$ & 1.49 & 2.73 & $* * *$ & 1.51 & 2.77 & $* * *$ \\
\hline SRI & -0.42 & -1.93 & $*$ & -0.19 & -1.03 & & -0.42 & -1.93 & $*$ \\
\hline D POS & 0.19 & 2.15 & $* *$ & 0.30 & 2.32 & $* *$ & & & \\
\hline D_POS $\times$ SRI & & & & -0.32 & -1.69 & $*$ & & & \\
\hline D_NEG & & & & & & & -0.19 & -2.15 & $* *$ \\
\hline OIMB_SAT & 0.04 & 0.26 & & 0.04 & 0.29 & & 0.04 & 0.26 & \\
\hline NBR_DEALERS & -0.07 & -3.26 & $* * *$ & -0.07 & -3.24 & $* * *$ & -0.07 & -3.26 & $* * *$ \\
\hline MV & 0.09 & 0.66 & & 0.08 & 0.65 & & 0.08 & 0.66 & \\
\hline HIGHLOW & 3.06 & 1.26 & & 3.05 & 1.27 & & 3.06 & 1.26 & \\
\hline VOLSHR & -0.02 & -2.37 & $* *$ & -0.02 & -2.35 & $* *$ & -0.02 & -2.37 & $* *$ \\
\hline Intercept & -0.60 & -0.2 & & -0.65 & -0.22 & & -0.41 & -0.13 & \\
\hline Time Dummies & Yes & & & Yes & & & Yes & & \\
\hline $\mathrm{N}$ & 1307 & & & 1307 & & & 1307 & & \\
\hline Adjusted R2 & 0.37 & & & 0.37 & & & 0.37 & & \\
\hline
\end{tabular}

\begin{tabular}{|c|c|c|c|c|c|c|c|c|c|}
\hline \multicolumn{10}{|c|}{ Panel B. } \\
\hline \multirow[t]{3}{*}{ Dependent variable: } & \multicolumn{9}{|c|}{ RSPREAD_SAT } \\
\hline & \multicolumn{3}{|c|}{$(1)$} & \multicolumn{3}{|c|}{$(2)$} & \multicolumn{3}{|c|}{$(3)$} \\
\hline & Coeff. & t-stat. & & Coeff. & t-stat. & & Coeff. & t-stat. & \\
\hline OIMB_DOM_EUR & 1.59 & 2.55 & $* *$ & 1.57 & 2.54 & $* *$ & 1.56 & 2.55 & ** \\
\hline SRI_EUR & -0.01 & -2.03 & $* *$ & -0.01 & -0.98 & & -0.01 & -2.03 & $*$ \\
\hline D_POS_EUR & 0.14 & 1.67 & $*$ & 0.24 & 2.1 & $* *$ & & & \\
\hline D_POS_EUR $\times$ SRI_EUR & & & & -0.01 & -2.59 & $* *$ & & & \\
\hline D_NEG_EUR & & & & & & & -0.14 & -1.67 & $*$ \\
\hline OIMB_SAT_EUR & 0.05 & 0.36 & & 0.04 & 0.33 & & 0.05 & 0.36 & \\
\hline NBR_DEALERS & -0.05 & -2.51 & $* *$ & -0.05 & -2.53 & $* *$ & -0.05 & -2.51 & $* *$ \\
\hline $\mathrm{MV}^{-}$ & -0.05 & -0.3 & & -0.05 & -0.3 & & -0.05 & -0.3 & \\
\hline HIGHLOW & 3.75 & 1.71 & $*$ & 3.75 & 1.72 & $*$ & 3.75 & 1.71 & $*$ \\
\hline VOLSHR & -0.01 & -0.61 & & -0.01 & -0.6 & & -0.01 & -0.61 & \\
\hline 1 / PRICE & -11.8 & -2.24 & $* *$ & -11.7 & -2.24 & $* *$ & -11.8 & -2.24 & $* *$ \\
\hline Intercept & 2.59 & 0.71 & & 2.51 & 0.69 & & 2.74 & 0.76 & \\
\hline Time Dummies & Yes & & & Yes & & & Yes & & \\
\hline $\mathrm{N}$ & 1307 & & & 1307 & & & 1307 & & \\
\hline Adjusted R2 & 0.4 & & & 0.4 & & & 0.4 & & \\
\hline
\end{tabular}




\section{Appendix - Proofs}

\section{Proof of Lemma 1}

Case 1. We first look for the necessary conditions that must be fulfilled simultaneously in order for an equilibrium characterized by the consolidation of the order flow to exist.

Dealer $i \in\{1,2\}$ trades the total fragmented order flow in equilibrium if and only if prices $p_{D}$ prevailing in market $D$ in which $Q_{D}>0$, and $p_{S}$ prevailing in market $S$ (in which $Q_{S}>0$ or $Q_{S}<0$ ) are the maximum (resp. minimum in market $S$ if $Q_{S}<0$ ) prices such that: (i) trading $Q_{D}+Q_{S}$ is profitable for dealer $i\left(v_{i}\left(Q_{D}+Q_{S}\right) \geq 0\right)$, but not for dealer $-i\left(v_{-i}\left(Q_{D}+Q_{S}\right)<0\right)$; (ii) for $m=\{D, S\}$, conditional on trading $Q_{m}$, dealer $i$ is willing to trade $Q_{-m}$, that is, $v_{i}\left(Q_{D}+Q_{S}\right) \geq v_{i}\left(Q_{S}\right)$ and $v_{i}\left(Q_{D}+Q_{S}\right) \geq v_{i}\left(Q_{D}\right)$; (iii) dealer $-i$ is not willing to undercut dealer $i$ neither in market $D$ nor in market $S$, that is, $v_{-i}\left(Q_{D}\right)<0$ and $v_{-i}\left(Q_{S}\right)<0$. Using the definition of dealers' reservation prices and trading profits, these conditions rewrite as follows:

$$
\begin{aligned}
& \text { i }: p_{D} Q_{D}+p_{S} Q_{S} \geq r_{i}\left(Q_{D}+Q_{S}\right)\left(Q_{D}+Q_{S}\right), \\
& \text { i' }: p_{D} Q_{D}+p_{S} Q_{S}<r_{-i}\left(Q_{D}+Q_{S}\right)\left(Q_{D}+Q_{S}\right) ; \\
& \text { ii }: p_{D} \geq r_{i}\left(Q_{D}\right)+\rho \sigma^{2} Q_{S} \\
& \text { ii' }: p_{S} Q_{S} \geq\left(r_{i}\left(Q_{S}\right)+\rho \sigma^{2} Q_{D}\right) Q_{S} \\
& \text { iii }: p_{D}<r_{-i}\left(Q_{D}\right) \\
& \text { iii' }: p_{S} Q_{S}<r_{-i}\left(Q_{S}\right) Q_{S}
\end{aligned}
$$

Suppose that dealer 1 trades $Q_{D}+Q_{S}$. If $\left(I_{1}-I_{2}-Q_{D}\right) Q_{S} \leq 0$, then $\left(r_{1}\left(Q_{S}\right)+\rho \sigma^{2} Q_{D}\right) Q_{S} \geq$ $r_{2}\left(Q_{S}\right) Q_{S}$, so conditions (ii') and (iii') cannot hold simultaneously. A necessary condition for such an equilibrium to exist is thus $\left(I_{1}-I_{2}-Q_{D}\right) Q_{S}>0$, i.e., either $I_{1}-I_{2}>Q_{D}$ if $Q_{S}>0$ or $I_{1}-I_{2}<Q_{D}$ if $Q_{S}<0$.

Suppose that dealer 2 trades $Q_{D}+Q_{S}$. Recall that by assumption $I_{1}>I_{2}$ (implying that $\left.r_{1}\left(Q_{D}+Q_{S}\right)<r_{2}\left(Q_{D}+Q_{S}\right)\right)$ and $Q_{D}+Q_{S}>0$. Thus conditions (i) and (i') cannot simultaneously hold for $i=2$. Therefore, there exists no such an equilibrium.

Case 2. We now look for the necessary conditions that must be fulfilled simultaneously for the existence of an equilibrium where dealers share the total fragmented order flow. 
At equilibrium, dealer $i \in\{1,2\}$ trades $Q_{D}$ and dealer $-i$ trades $Q_{S}$ if and only if prices $p_{D}$ prevailing in market $D$ where $Q_{D}>0$, and $p_{S}$ prevailing in market $S$ (where $Q_{S}$ is either positive or negative) are the maximum (resp. minimum in market $S$ if $Q_{S}<0$ ) prices such that: (I) dealer $i$ is better off trading $Q_{D}$ rather than $Q_{S}\left(v_{i}\left(Q_{D}\right)>v_{i}\left(Q_{S}\right)\right)$ and dealer $-i$ is better off trading $Q_{S}$ rather than $Q_{D}\left(v_{-i}\left(Q_{S}\right)>v_{-i}\left(Q_{D}\right)\right)$; (II) dealer $-i$ is better off trading $Q_{S}$ only rather than $Q_{D}+Q_{S}\left(v_{-i}\left(Q_{D}+Q_{S}\right)<v_{-i}\left(Q_{S}\right)\right)$ and dealer $i$ is better off trading $Q_{D}$ only rather than $Q_{D}+Q_{S}\left(v_{i}\left(Q_{D}+Q_{S}\right)<v_{i}\left(Q_{D}\right)\right) ;(\mathrm{III})$ trading $Q_{D}$ is profitable for dealer $i\left(v_{i}\left(Q_{D}\right) \geq 0\right)$ and trading $Q_{S}$ is profitable for dealer $-i\left(v_{i}\left(Q_{S}\right) \geq 0\right)$. These latter conditions may be rewritten as follows:

$$
\begin{aligned}
& \text { I }: p_{D}>r_{i}\left(Q_{D}\right)+\left(p_{S}-r_{i}\left(Q_{S}\right)\right) \frac{Q_{S}}{Q_{D}} \\
& \text { I'}^{\prime}: p_{S} Q_{S}>r_{-i}\left(Q_{S}\right) Q_{S}+\left(p_{D}-r_{-i}\left(Q_{D}\right)\right) Q_{D} \\
& \text { II }: p_{D}<r_{-i}\left(Q_{D}\right)+\rho \sigma^{2} Q_{S} \\
& \text { II' }: p_{S} Q_{S}<\left(r_{i}\left(Q_{S}\right)+\rho \sigma^{2} Q_{D}\right) Q_{S} \\
& \text { III }: p_{D} \geq r_{i}\left(Q_{D}\right) \\
& \text { III' }: p_{S} Q_{S} \geq r_{-i}\left(Q_{S}\right) Q_{S}
\end{aligned}
$$

Suppose that dealer 1 trades $Q_{D}$ and dealer 2 trades $Q_{S}$. If $\left(I_{1}-I_{2}-Q_{D}\right) Q_{S} \geq 0$, then conditions II' and III' cannot hold simultaneously. A necessary condition for such an equilibrium to exist is thus $\left(I_{1}-I_{2}-Q_{D}\right) Q_{S}<0$, that is, either $I_{1}-I_{2}<Q_{D}$ if $Q_{S}>0$ or $I_{1}-I_{2}>Q_{D}$ if $Q_{S}<0$.

Suppose that dealer 1 trades $Q_{S}$ and dealer 2 trades $Q_{D}$. If $Q_{S}<0$, then conditions II and III cannot hold simultaneously, since $r_{1}\left(Q_{D}\right)+\rho \sigma^{2} Q_{S}<r_{2}\left(Q_{D}\right)$. If $Q_{S}>0$, a necessary condition for conditions I and I' to hold simultaneously is

$$
r_{1}\left(Q_{S}\right)+\left(p_{D}-r_{1}\left(Q_{D}\right)\right) \frac{Q_{D}}{Q_{S}}<r_{2}\left(Q_{S}\right)+\left(p_{D}-r_{2}\left(Q_{D}\right)\right) \frac{Q_{D}}{Q_{S}}
$$

which is never true since $I_{1}>I_{2}$ and $\left|Q_{D}\right|>\left|Q_{S}\right|$. Consequently, there exists no equilibrium in which the longer dealer (here, dealer 1) would be the first buyer in market $S$ while the shorter dealer 2 would be the first seller in market D. Q.E.D.

Case 3. Suppose finally that $\left(I_{1}-I_{2}-Q_{D}\right) Q_{S}=0$, then $\left(r_{1}\left(Q_{S}\right)+\rho \sigma^{2} Q_{D}\right) Q_{S}=$ 
$r_{2}\left(Q_{S}\right) Q_{S}$. Dealers 1 and 2 have the same reservation prices for $Q_{S}$ in market $S$. Consequenly both are equally likely to execute $Q_{S}$.

\section{Proof of Proposition 1}

From Lemma 1, there are two cases to consider when $Q_{S}>0$ :

Case 1: $I_{1}-I_{2}>Q_{D}$, i.e., $\left(I_{1}-I_{2}-Q_{D}\right) Q_{S}>0$. From Lemma 1, we know that dealer 1 consolidates the total fragmented order flow by posting the best ask prices in both market $D$ and $S$. The ask prices $p_{D}$ and $p_{S}$ must satisfy the set of conditions i to iii' (Case 1 in Lemma 1) given that $Q_{S}>0$ and $I_{1}-I_{2}>Q_{D}$ and are the maximum prices such that:

$$
\begin{aligned}
& \text { ii and iii : } r_{1}\left(Q_{D}\right)+\rho \sigma^{2} Q_{S} \leq p_{D}<r_{2}\left(Q_{D}\right) \\
& \text { ii' and iii' }: r_{1}\left(Q_{S}\right)+\rho \sigma^{2} Q_{D} \leq p_{S}<r_{2}\left(Q_{S}\right) \\
& \text { i }: r_{1}\left(Q_{D}+Q_{S}\right)\left(Q_{D}+Q_{S}\right) \leq p_{D} Q_{D}+p_{S} Q_{S} \\
& \text { i' }: p_{D} Q_{D}+p_{S} Q_{S}<r_{2}\left(Q_{D}+Q_{S}\right)\left(Q_{D}+Q_{S}\right)
\end{aligned}
$$

From the two first inequalities, $\left(p_{D}\right)^{*}=r_{2}\left(Q_{D}\right)-\varepsilon$ and $\left(p_{S}\right)^{*}=r_{2}\left(Q_{S}\right)-\varepsilon$ are natural candidates for the equilibrium, as they are the maximum prices that satisfy conditions ii, ii', iii and iii'. It is easily shown that they also satisfy conditions i and i' (details are omitted for brevity).

Case 2: $I_{1}-I_{2}<Q_{D}$, i.e., $\left(I_{1}-I_{2}-Q_{D}\right) Q_{S}<0$. In this case, dealer 1 executes $Q_{D}$ while dealer 2 executes $Q_{S}$ (see Lemma 1). Given the set of conditions I to III' and under the hypotheses that $Q_{S}>0$ and $I_{1}-I_{2}<Q_{D}$, the ask prices $p_{D}$ and $p_{S}$ are the maximum prices such that:

$$
\begin{array}{r}
\text { II and III }: r_{1}\left(Q_{D}\right) \leq p_{D}<r_{2}\left(Q_{D}\right)+\rho \sigma^{2} Q_{S} \\
\text { II' and III' }: r_{2}\left(Q_{S}\right) \leq p_{S}<r_{1}\left(Q_{S}\right)+\rho \sigma^{2} Q_{D} \\
\text { I }: p_{D}>r_{1}\left(Q_{D}\right)+\left(p_{S}-r_{1}\left(Q_{S}\right)\right) \frac{Q_{S}}{Q_{D}} \\
\text { I' }: p_{S}>r_{2}\left(Q_{S}\right)+\left(p_{D}-r_{2}\left(Q_{D}\right)\right) \frac{Q_{D}}{Q_{S}}
\end{array}
$$

The natural candidates for the equilibrium $p_{D}=r_{2}\left(Q_{D}\right)+\rho \sigma^{2} Q_{S}-\varepsilon$ and $p_{S}=r_{1}\left(Q_{S}\right)+$ $\rho \sigma^{2} Q_{D}-\varepsilon$ from the two first inequalities do not satisfy condition I'. Consequently, the 
constraint I' is binding at equilibrium, and equilibrium prices must be such that:

$$
\left(p_{D}\right)^{*}=r_{2}\left(Q_{D}\right)+\left(\left(p_{S}\right)^{*}-r_{2}\left(Q_{S}\right)\right) \frac{Q_{S}}{Q_{D}}-\varepsilon
$$

First, notice that under the latter condition, condition I always holds (given that $\left(I_{1}-\right.$ $\left.\left.I_{2}\right)\left(Q_{D}-Q_{S}\right)>0\right)$. Second, inputting $\left(p_{D}\right)^{*}$ defined in Eq.(8) into conditions (II and III) and (II' and III') yields the following restrictions on $\left(p_{S}\right)^{*}$ :

$$
\begin{aligned}
& \text { II and III: } r_{2}\left(Q_{S}\right)+\left(r_{1}\left(Q_{D}\right)-r_{2}\left(Q_{D}\right)\right) \frac{Q_{D}}{Q_{S}} \leq\left(p_{S}\right)^{*}<r_{2}\left(Q_{S}\right)+\rho \sigma^{2} Q_{D} \\
& \text { II' and III': } r_{2}\left(Q_{S}\right) \leq\left(p_{S}\right)^{*}<r_{1}\left(Q_{S}\right)+\rho \sigma^{2} Q_{D}
\end{aligned}
$$

Third, we input $\left(p_{D}\right)^{*}$ (defined in Eq.(8)) in both the trading profit of dealer 1, conditional on the fact that she executes $Q_{D}$, and the trading profit of dealer 2, conditional on the fact that he executes $Q_{S}$ :

$$
\begin{aligned}
& v_{1}\left(Q_{D}\right)=\left(r_{2}\left(Q_{D}\right)+\left(\left(p_{S}\right)^{*}-r_{2}\left(Q_{S}\right)\right) \frac{Q_{S}}{Q_{D}}-r_{1}\left(Q_{D}\right)\right) Q_{D} \\
& v_{2}\left(Q_{S}\right)=\left(\left(p_{S}\right)^{*}-r_{2}\left(Q_{S}\right)\right) Q_{S} .
\end{aligned}
$$

We observe that dealers' profits are strictly increasing in $p_{S}$. Consequently, dealers' reaction functions are such that the best ask price in market $S$ is the highest possible one. From conditions (II and III) and (II' and III'), and under the hypothesis that $I_{1}-I_{2}<Q_{D}$, we deduce that condition (II' and III') is binding and that $\left(p_{S}\right)^{*}$ is such that:

$$
\left(p_{S}\right)^{*}=r_{1}\left(Q_{S}\right)+\rho \sigma^{2} Q_{D}-\varepsilon
$$

from which we deduce that

$$
\left(p_{D}\right)^{*}=r_{2}\left(Q_{D}\right)+\rho \sigma^{2}\left(I_{2}-I_{1}+Q_{D}\right) \frac{Q_{S}}{Q_{D}}-\varepsilon
$$

Consequently, there exists a unique equilibrium such that dealer 1 post $a_{1}^{+L}=\left(a_{D}^{+L}\right)^{*}=$ $\left(p_{D}\right)^{*}$ and trades $Q_{D}$ while dealer 2 posts the best ask price equal to $\left(p_{S}\right)^{*}$ and trades $Q_{S}$. Q.E.D.

\section{Proof of Proposition 2}


There are two cases to consider when $Q_{S}<0$ (see Lemma 1):

Case 1: $I_{1}-I_{2}>Q_{D}$, i.e., $\left(I_{1}-I_{2}-Q_{D}\right) Q_{S}<0$. In this case, dealers share the total fragmented order flow. Equilibrium prices must satisfy condition I to III' (see Case 2 in the proof of Lemma 1), under the hypotheses that $Q_{S}<0$ and $I_{1}-I_{2}>Q_{D}$. Prices are thus such that:

$$
\begin{aligned}
& \text { II and III }: r_{1}\left(Q_{D}\right) \leq p_{D}<r_{2}\left(Q_{D}\right)+\rho \sigma^{2} Q_{S} \\
& \text { II' and III' }: r_{1}\left(Q_{S}\right)+\rho \sigma^{2} Q_{D}<p_{S} \leq r_{2}\left(Q_{S}\right) \\
& \text { I }: p_{D}>r_{1}\left(Q_{D}\right)+\left(p_{S}-r_{1}\left(Q_{S}\right)\right) \frac{Q_{S}}{Q_{D}} \\
& \text { I' }: p_{S}<r_{2}\left(Q_{S}\right)+\left(r_{2}\left(Q_{D}\right)-p_{D}\right) \frac{Q_{D}}{-Q_{S}}
\end{aligned}
$$

From the two first inequalities, $p_{D}=r_{2}\left(Q_{D}\right)-\rho \sigma^{2}\left(-Q_{S}\right)-\varepsilon$ and $p_{S}=r_{1}\left(Q_{S}\right)+\rho \sigma^{2} Q_{D}+$ $\varepsilon$ are natural candidates for the equilibrium. It is easily shown that they also satisfy conditions I and I'. Therefore, there exists a unique equilibrium such that dealer 1 posts the best ask price in market $D$, equal to $\left(a_{D}^{-H}\right)^{*}=\left(p_{D}\right)^{*}=r_{2}\left(Q_{D}\right)-\rho \sigma^{2}\left(-Q_{S}\right)-\varepsilon$ while dealer 2 posts the best ask in market $S$ equal to $\left(a_{S}^{-H}\right)^{*}=\left(p_{S}\right)^{*}$.

Case 2: $I_{1}-I_{2}<Q_{D}$, i.e., $\left(I_{1}-I_{2}-Q_{D}\right) Q_{S}>0$. Dealer 1 trades the total fragmented order flow (see Lemma 1 ). The ask price $p_{D}$ in market $D$ and the bid price $p_{S}$ in market $S$ must satisfy the set of conditions i to iii' and are such that:

$$
\begin{aligned}
& \text { ii and iii : } r_{1}\left(Q_{D}\right)-\rho \sigma^{2}\left(-Q_{S}\right) \leq p_{D}<r_{2}\left(Q_{D}\right) \\
& \text { ii' and iii' }: r_{2}\left(Q_{S}\right)<p_{S} \leq r_{1}\left(Q_{S}\right)+\rho \sigma^{2} Q_{D} \\
& \quad \text { i and i' }: r_{1}\left(Q_{D}+Q_{S}\right)\left(Q_{D}+Q_{S}\right) \leq p_{D} Q_{D}+p_{S} Q_{S}<r_{2}\left(Q_{D}+Q_{S}\right)\left(Q_{D}+Q_{S}\right)
\end{aligned}
$$

The natural candidates for the equilibrium $p_{D}=r_{2}\left(Q_{D}\right)-\varepsilon$ and $p_{S}=r_{2}\left(Q_{S}\right)+\varepsilon$ do not satisfy condition i'. Consequently, the constraint i' is binding at equilibrium, and equilibrium prices must be such that:

$$
\left(p_{D}\right)^{*}=r_{2}\left(Q_{D}+Q_{S}\right)+\left(p_{S}^{*}-r_{2}\left(Q_{D}+Q_{S}\right)\right) \frac{\left(-Q_{S}\right)}{Q_{D}}-\varepsilon
$$

First, we use the expression of $\left(p_{D}\right)^{*}$ in dealer 1's trading profit (conditional on the fact 
that she executes $Q_{D}$ and $\left.Q_{S}\right): v_{1}^{-L}\left(Q_{D}+Q_{S}\right)=\rho \sigma^{2}\left(I_{1}-I_{2}\right)\left(Q_{D}+Q_{S}\right)$. This trading profit does not depend on equilibrium prices. Consequently, there may exist a continuum of prices that may sustain the equilibrium. Second, inputing $\left(p_{D}\right)^{*}$ into conditions ii to iii', the equilibrium price in market $S$ must satisfy:

$$
\begin{aligned}
& \text { ii and iii : }\left(r_{1}-r_{2}\right) \frac{Q_{D}}{-Q_{S}}+r_{2}\left(Q_{S}\right) \leq\left(p_{S}\right)^{*}<\left(r_{2}-r_{1}\right) \frac{Q_{D}}{-Q_{S}}+r_{2}\left(Q_{S}\right)-\rho \sigma^{2} Q_{D} \\
& \text { ii' and iii' }: r_{2}\left(Q_{S}\right)<\left(p_{S}\right)^{*} \leq r_{1}\left(Q_{S}\right)+\rho \sigma^{2} Q_{D}
\end{aligned}
$$

Obviously, since $I_{1}>I_{2},\left(r_{1}-r_{2}\right) \frac{Q_{D}}{-Q_{S}}<r_{2}\left(Q_{S}\right)$ and $r_{1}\left(Q_{S}\right)+\rho \sigma^{2} Q_{D}<\left(r_{2}-r_{1}\right) \frac{Q_{D}}{-Q_{S}}+$ $r_{2}\left(Q_{S}\right)-\rho \sigma^{2} Q_{D}$ so the second inequality is constraining both the minimum and the maximum possible price in market $S$. Within all equilibria defined by:

$$
\begin{aligned}
& \left(p_{D}\right)^{*}=r_{2}\left(Q_{D}+Q_{S}\right) \frac{Q_{D}+Q_{S}}{Q_{D}}+\left(p_{S}\right)^{*} \frac{\left(-Q_{S}\right)}{Q_{D}}-\varepsilon, \\
& \left(p_{S}\right)^{*} \in\left(r_{2}\left(Q_{S}\right), r_{1}\left(Q_{S}\right)+\rho \sigma^{2} Q_{D}\right],
\end{aligned}
$$

we select the only equilibrium that is continuous at $I_{1}-I_{2}=Q_{D}$, that is, $\left(p_{S}\right)^{*}=$ $r_{1}\left(Q_{S}\right)+\rho \sigma^{2} Q_{D}$, from which we deduce that $\left(p_{D}\right)^{*}=r_{2}\left(Q_{D}\right)+\rho \sigma^{2} Q_{S}$. Q.E.D.

\section{Proof of Proposition 3}

We decompose the proof into two results, depending on the sign of $Q_{S}$, that is, on whether $\gamma=1$ or $\gamma=0$.

Result 1 (Same signs) Suppose that $\lambda_{S}=\lambda_{D}=1$ and that order flows have same signs $(\gamma=1)$. The expected ask prices in the dominant $(D)$ and the satellite $(S)$ markets are equal to:

$$
E\left(\underline{a}^{m,+}\right)=\frac{2 r_{d}\left(Q_{m}\right)+r_{u}\left(Q_{m}\right)}{3}+\rho \sigma^{2} Q_{-m}\left(\frac{\rho \sigma^{2} Q_{D}}{r_{d}-r_{u}}-\frac{1}{3}\left(\frac{\rho \sigma^{2} Q_{D}}{r_{d}-r_{u}}\right)^{2}\right), m=S, D
$$

Proof. We first compute the expected ask that prevails in market $D$. For sake of brevity, 
let us define $r_{d}\left(Q_{D}\right)=r_{d}, r_{u}\left(Q_{D}\right)=r_{u}, r_{1}\left(Q_{D}\right)=x$ and $r_{2}\left(Q_{S}\right)=y$.

$$
\begin{aligned}
E\left(\underline{a}^{D,+}\right) & =E\left(\min \left(a_{1}^{D,+}, a_{2}^{D,+}\right)\right) \\
& =E\left(\begin{array}{c}
r_{2}\left(Q_{S}\right) \mathbb{1}_{r_{1}\left(Q_{S}\right)+\rho \sigma^{2} Q_{D}<r_{2}\left(Q_{S}\right)}+\left(r_{1}\left(Q_{S}\right)+\rho \sigma^{2} Q_{D}\right) \mathbb{1}_{r_{1}\left(Q_{S}\right)+\rho \sigma^{2} Q_{D}>r_{2}\left(Q_{S}\right)} \\
+r_{1}\left(Q_{S}\right) \mathbb{1}_{r_{2}\left(Q_{S}\right)+\rho \sigma^{2} Q_{D}<r_{1}\left(Q_{S}\right)}+\left(r_{2}\left(Q_{S}\right)+\rho \sigma^{2} Q_{D}\right) \mathbb{1}_{r_{2}\left(Q_{S}\right)+\rho \sigma^{2} Q_{D}>r_{1}\left(Q_{S}\right)}
\end{array}\right)
\end{aligned}
$$

or

$$
\begin{aligned}
E\left(\underline{a}^{D,+}\right) & =\frac{1}{\left(r_{d}-r_{u}\right)^{2}}\left[\int_{r_{u}}^{r_{d}-\rho \sigma^{2} Q_{D}} \int_{x+\rho \sigma^{2} Q_{D}}^{r_{d}} y d y d x+\int_{r_{u}+\rho \sigma^{2} Q_{D}}^{r_{d}} \int_{r_{u}}^{x-\rho \sigma^{2} Q_{D}} x d y d x\right. \\
& +\int_{r_{u}}^{r_{d}} \int_{x}^{r_{d}}\left(y+\rho \sigma^{2} Q_{S}\left(\frac{\rho \sigma^{2} Q_{D}-(y-x)}{\rho \sigma^{2} Q_{D}}\right)\right) d y d x \\
& -\int_{r_{u}}^{r_{d}-\rho \sigma^{2} Q_{D}} \int_{x+\rho \sigma^{2} Q_{D}}^{r_{d}}\left(y+\rho \sigma^{2} Q_{S}\left(\frac{\rho \sigma^{2} Q_{D}-(y-x)}{\rho \sigma^{2} Q_{D}}\right)\right) d y d x \\
& +\int_{r_{u}}^{r_{d}} \int_{r_{u}}^{x}\left(x+\rho \sigma^{2} Q_{S}\left(\frac{\rho \sigma^{2} Q_{D}-(x-y)}{\rho \sigma^{2} Q_{D}}\right)\right) d y d x \\
& \left.-\int_{r_{u}+\rho \sigma^{2} Q_{D}}^{r_{d}} \int_{r_{u}}^{x-\rho \sigma^{2} Q_{D}}\left(x+\rho \sigma^{2} Q_{S}\left(\frac{\rho \sigma^{2} Q_{D}-(x-y)}{\rho \sigma^{2} Q_{D}}\right)\right) d y d x\right] .
\end{aligned}
$$

After straightforward calculations, we get:

$$
E\left(\underline{a}^{D,+}\right)=\frac{2 r_{d}\left(Q_{D}\right)+r_{u}\left(Q_{D}\right)}{3}+\rho \sigma^{2} Q_{S}\left(\frac{\rho \sigma^{2} Q_{D}}{\left(r_{d}-r_{u}\right)}-\frac{\left(\rho \sigma^{2} Q_{D}\right)^{2}}{3\left(r_{d}-r_{u}\right)^{2}}\right)
$$

We now turn to the expected ask prevailing in market $S$ when $\gamma=1$. This expression writes:

$$
\begin{aligned}
E\left(\underline{a}^{S,+}\right) & =E\left(\min \left(a_{1}^{S,+}, a_{2}^{S,+}\right)\right) \\
& =E\left(\begin{array}{c}
r_{2}\left(Q_{S}\right) \mathbb{1}_{r_{1}\left(Q_{S}\right)+\rho \sigma^{2} Q_{D}<r_{2}\left(Q_{S}\right)}+\left(r_{1}\left(Q_{S}\right)+\rho \sigma^{2} Q_{D}\right) \mathbb{1}_{r_{1}\left(Q_{S}\right)+\rho \sigma^{2} Q_{D}>r_{2}\left(Q_{S}\right)} \\
+r_{1}\left(Q_{S}\right) \mathbb{1}_{r_{2}\left(Q_{S}\right)+\rho \sigma^{2} Q_{D}<r_{1}\left(Q_{S}\right)}+\left(r_{2}\left(Q_{S}\right)+\rho \sigma^{2} Q_{D}\right) \mathbb{1}_{r_{2}\left(Q_{S}\right)+\rho \sigma^{2} Q_{D}>r_{1}\left(Q_{S}\right)}
\end{array}\right)
\end{aligned}
$$

Using a similar reasoning and straightforward computations to those used in the previous case, the latter expression rewrites:

$$
E\left(\underline{a}^{S,+}\right)=\frac{2 r_{d}+r_{u}}{3}+\rho \sigma^{2} Q_{D}\left(\frac{\left(\rho \sigma^{2} Q_{D}\right)}{\left(r_{d}-r_{u}\right)}-\frac{\left(\rho \sigma^{2} Q_{D}\right)^{2}}{3\left(r_{d}-r_{u}\right)^{2}}\right)
$$


Q.E.D.

Result 2 (Opposite signs) Suppose that $\lambda_{S}=\lambda_{D}=1$ and that order flows have opposite signs $(\gamma=0)$. The expected asks in markets $D$ and $S$ respectively write:

$$
\begin{aligned}
& E\left(\underline{a}^{D,-}\right)=\frac{2 r_{d}\left(q_{D}\right)+r_{u}\left(q_{D}\right)}{3}-\rho \sigma^{2} q_{S} \\
& E\left(\underline{a}^{S,-}\right)=\frac{2 r_{d}\left(q_{S}\right)+r_{u}\left(q_{S}\right)}{3}-\rho \sigma^{2} q_{D}+\frac{\left(\rho \sigma^{2} q_{D}\right)^{2}}{\left(r_{d}-r_{u}\right)}-\frac{\left(\rho \sigma^{2} q_{D}\right)^{3}}{3\left(r_{d}-r_{u}\right)^{2}} .
\end{aligned}
$$

Proof. We first compute the expected ask prevailing in market $D$ (for $Q_{D}>0$ and $\left.Q_{S}<0\right)$. Straightforward computations yield:

$$
\begin{aligned}
E\left(\underline{a}^{D,-}\right) & =E\left(\min \left(a_{1}^{D,-}, a_{2}^{D,-}\right)\right) \\
& =\frac{2 r_{d}\left(Q_{D}\right)+r_{u}\left(Q_{D}\right)}{3}-\rho \sigma^{2}\left(-Q_{S}\right) .
\end{aligned}
$$

Symmetrically, the expected ask prevailing in market $S$, and considering that $Q_{D}<0$ and $Q_{S}>0$, writes:

$$
\begin{aligned}
E\left(\underline{a}^{S,-}\right) & =E\left(\min \left(a_{1}^{S,-}, a_{2}^{S,-}\right)\right) \\
& =E\left(\begin{array}{c}
r_{2}\left(Q_{S}\right) \mathbb{1}_{r_{2}\left(Q_{S}\right)>r_{1}\left(Q_{S}\right)-\rho \sigma^{2}\left(-Q_{D}\right)}+\left(r_{1}\left(Q_{S}\right)-\rho \sigma^{2}\left(-Q_{D}\right)\right) \mathbb{1}_{r_{2}\left(Q_{S}\right)<r_{1}\left(Q_{S}\right)-\rho \sigma^{2}\left(-Q_{D}\right)} \\
+r_{1}\left(Q_{S}\right) \mathbb{1}_{r_{1}\left(Q_{S}\right)>r_{2}\left(Q_{S}\right)-\rho \sigma^{2}\left(-Q_{D}\right)}+\left(r_{2}\left(Q_{S}\right)-\rho \sigma^{2}\left(-Q_{D}\right)\right) \mathbb{1}_{r_{1}\left(Q_{S}\right)<r_{2}\left(Q_{S}\right)-\rho \sigma^{2}\left(-Q_{D}\right)}
\end{array}\right)
\end{aligned}
$$

or

$$
\begin{aligned}
E\left(\underline{a}^{S,-}\right) & =\frac{1}{\left(r_{d}-r_{u}\right)^{2}}\left[\int_{r_{u}+\rho \sigma^{2}\left(-Q_{D}\right)}^{r_{d}} \int_{r_{u}}^{x-\rho \sigma^{2}\left(-Q_{D}\right)}\left(x-\rho \sigma^{2}\left(-Q_{D}\right)\right) d y d x\right. \\
& +\int_{r_{u}}^{r_{d}-\rho \sigma^{2}\left(-Q_{D}\right)} \int_{x+\rho \sigma^{2}\left(-Q_{D}\right)}^{r_{d}}\left(y-\rho \sigma^{2}\left(-Q_{D}\right)\right) d y d x \\
& +\left(\int_{r_{u}}^{r_{d}} \int_{x}^{r_{d}}\left(x+\rho \sigma^{2} Q_{D}\right) d y d x-\int_{r_{u}}^{r_{d}-\rho \sigma^{2} Q_{D}} \int_{x+\rho \sigma^{2} Q_{D}}^{r_{d}} y d y d x\right) \\
& \left.+\left(\int_{r_{u}}^{r_{d}} \int_{r_{u}}^{x}\left(y+\rho \sigma^{2} Q_{D}\right) d y d x-\int_{r_{u}+\rho \sigma^{2} Q_{D}}^{r_{d}} \int_{r_{u}}^{x-\rho \sigma^{2} Q_{D}}\left(y+\rho \sigma^{2} Q_{D}\right) d y d x\right)\right] .
\end{aligned}
$$


This latter expression rewrites:

$$
E\left(\underline{a}^{S,-}\right)=\frac{2 r_{d}\left(Q_{S}\right)+r_{u}\left(Q_{S}\right)}{3}-\rho \sigma^{2}\left(-Q_{D}\right)+\frac{\left(\rho \sigma^{2}\left(-Q_{D}\right)\right)^{2}}{\left(r_{d}-r_{u}\right)}-\frac{\left(\rho \sigma^{2}\left(-Q_{D}\right)\right)^{3}}{3\left(r_{d}-r_{u}\right)^{2}} .
$$

Q.E.D.

Proposition 3 is obtained from Results 1 and 2 considering the extensive form of the game represented in Figure 1. Note that we change slightly notations $q_{m}=Q_{m}$ for a net-buying order flow and $q_{m}=-Q_{m}$ for a net-selling order flow $(m=S, D)$ in order to ease computations of Corollaries 1 and 2. Q.E.D.

\section{Proof of Corollary 1}

Part 1. Expected asks in market $m$ increase when $\gamma$ increases $(m=S, D)$ since $\partial E\left(\underline{a}^{S}\right) / \partial \gamma=\rho \sigma^{2} q_{D}>0$ and $\partial E\left(\underline{a}^{D}\right) / \partial \gamma=-\rho \sigma^{2} q_{S}\left(\frac{q_{D}}{\left(I_{u}-I_{d}\right)}-\frac{3+\sqrt{21}}{2}\right)\left(\frac{q_{D}}{\left(I_{u}-I_{d}\right)}-\frac{3-\sqrt{21}}{2}\right)>$ 0 since $q_{D}>0$ and $q_{D} \leq\left(I_{u}-I_{d}\right)<\frac{3+\sqrt{21}}{2}\left(I_{u}-I_{d}\right)$.

Part 2. The expected best offer in market $D$ varies with $q_{S}$ as follows:

$$
\begin{aligned}
\frac{\partial E\left(\underline{a}^{D}\right)}{\partial q_{S}} & =\rho \sigma^{2}\left(\gamma\left(\frac{\rho \sigma^{2} q_{D}}{r_{d}-r_{u}}-\frac{1}{3}\left(\frac{\rho \sigma^{2} q_{D}}{r_{d}-r_{u}}\right)^{2}\right)-(1-\gamma)\right) \\
& =-\rho \sigma^{2}\left(\frac{q_{D}}{\left.I_{u}-I_{d}\right)}-q_{D}^{*}(\gamma)\right)\left(\frac{q_{D}}{I_{u}-I_{d}}-q_{D}^{*^{\prime}}(\gamma)\right) .
\end{aligned}
$$

where $q_{D}^{*}(\gamma)=(3 / 2-\sqrt{3} \sqrt{-1 / \gamma+7 / 4})\left(I_{u}-I_{d}\right)$ and $q_{D}^{*^{\prime}}(\gamma)=(3 / 2+\sqrt{3} \sqrt{-1 / \gamma+7 / 4})\left(I_{u}-I_{d}\right)$. Under our assumption, $q_{D}<q_{D}^{*^{\prime}}(\gamma)$. We can thus deduce that the best offer in market $D$ decreases with $q_{D}$ if $q_{D}<q_{D}^{*}(\gamma)$. Note that, in particular, if $\gamma=0$, then $\partial E\left(\underline{a}^{D}\right) / \partial q_{S}=-\rho \sigma^{2}<0$. If $\gamma=1$, then $\partial E\left(\underline{a}^{D}\right) / \partial q_{S}=\frac{1}{3} \rho \sigma^{2} \frac{q_{D}}{\left(I_{u}-I_{d}\right)}\left(3-\frac{q_{D}}{\left(I_{u}-I_{d}\right)}\right)>0$ (by assumption $q_{D} \leq\left(I_{u}-I_{d}\right)$ ).

Let us now turn to the analysis of the expected best offer in market $S$ when $q_{D}$ varies:

$$
\frac{\partial E\left(\underline{a}^{S}\right)}{\partial q_{D}}=-\rho \sigma^{2}\left(\frac{q_{D}}{I_{u}-I_{d}}-(1-\sqrt{\gamma})\right)\left(\frac{q_{D}}{I_{u}-I_{d}}-(1+\sqrt{\gamma})\right) .
$$

This implies that $\frac{\partial E\left(\underline{a}^{S}\right)}{\partial q_{D}}<0$ when $q_{D}<q_{D}^{* *}(\gamma)$ where $q_{D}^{* *}(\gamma)=(1-\sqrt{\gamma})\left(I_{u}-I_{d}\right)$. We can also notice that, if $\gamma=0$, then $\frac{\partial E\left(\underline{a}^{S}\right)}{\partial q_{D}}=-\rho \sigma^{2}\left(\frac{q_{D}}{I_{u}-I_{d}}-1\right)^{2}<0$. If $\gamma=1$, then $\frac{\partial E\left(\underline{a}^{S}\right)}{\partial q_{D}}=-\rho \sigma^{2} \frac{q_{D}}{I_{u}-I_{d}}\left(\frac{q_{D}}{I_{u}-I_{d}}-2\right)>0$ since, by assumption, $q_{D}<\left(I_{u}-I_{d}\right)$. Q.E.D. 


\section{Proof of Corollary 2}

Remind that $\underline{a}^{H S}$ denotes the minimum ask price in the benchmark model in which the total order flow is consolidated. From Ho and Stoll (1983), we know that:

$$
E\left(\underline{a}^{H S}\right)=\frac{2 r_{d}\left(q_{m}+q_{-m}\right)+r_{u}\left(q_{m}+q_{-m}\right)}{3} .
$$

Using Eq. (12) and (16) and the symmetry of the game, we deduce that the difference in transactions costs between a fragmented or a consolidated order flow is:

$$
\begin{aligned}
\Delta T C & =\gamma\left(E\left(\underline{a}^{D,+}\right) q_{D}+E\left(\underline{a}^{S,+}\right) q_{S}-E\left(\underline{a}^{H S}\right)\left(q_{D}+q_{S}\right)\right) \\
& +(1-\gamma)\left(E\left(\underline{a}^{D,-}\right) q_{D}-E(\bar{b}) q_{S}-E\left(\underline{a}^{H S}\right)\left(q_{D}-q_{S}\right)\right) .
\end{aligned}
$$

After straightforward computations the latter expression is equal to:

$$
\Delta T C=\rho \sigma^{2} q_{S}\left(I_{u}-I_{d}\right)\left(-\frac{(\gamma+1)}{3}\right) P_{\gamma}\left(\frac{q_{D}}{I_{u}-I_{d}}\right)
$$

where

$$
P_{\gamma}(x)=x^{3}-3 x^{2}+\frac{3}{(\gamma+1)} x+\frac{(\gamma-1)}{(\gamma+1)}
$$

for $x \in[0,1]$. Let us analyze the sign of this cubic polynomial. First, note that:

$$
P_{\gamma}^{\prime}(x)=3 x^{2}-6 x+\frac{3}{(1+\gamma)}=3\left(x-\left(1-\sqrt{\frac{\gamma}{1+\gamma}}\right)\right)\left(x-\left(1+\sqrt{\frac{\gamma}{1+\gamma}}\right)\right)
$$

Given that $x \in[0,1]$, then $x-\left(1+\sqrt{\frac{\gamma}{1+\gamma}}\right)<0$, and the sign of $P_{\gamma}^{\prime}(x)$ only depends on the sign of $\left(x-\left(1-\sqrt{\frac{\gamma}{1+\gamma}}\right)\right) . P_{\gamma}$ is increasing if $x<\left(1-\sqrt{\frac{\gamma}{1+\gamma}}\right)$ and is decreasing if $x>$ $\left(1-\sqrt{\frac{\gamma}{1+\gamma}}\right)$. Then, the local maximum is $P_{\gamma}\left(1-\sqrt{\frac{\gamma}{1+\gamma}}\right)=\frac{\gamma\left(-1+2 \sqrt{\frac{\gamma}{1+\gamma}}\right)}{1+\gamma}$. Straightforward computations show that $P_{\gamma}\left(1-\sqrt{\frac{\gamma}{1+\gamma}}\right) \leq 0$ if $\gamma \leq \frac{1}{3} \quad\left(\right.$ with $P_{\gamma}\left(1-\sqrt{\frac{\gamma}{1+\gamma}}\right)=0$ if $\left.\gamma=\frac{1}{3}\right)$. We therefore deduce that $P_{\gamma} \leq 0$, i.e., $\Delta T C \geqslant 0$ if $\gamma \leq \frac{1}{3}$. If $\gamma>\frac{1}{3}$, then $P_{\gamma}>0$, or, equivalently, $\Delta T C<0$ if $x \in\left[r_{\gamma}^{1}, r_{\gamma}^{2}\right]$ where $P_{\gamma}\left(r_{\gamma}^{1}\right)=0=P_{\gamma}\left(r_{\gamma}^{2}\right)$. Note that if $\gamma=1$, then it is direct to show that $P_{1}>0$ if $x \in\left[0, \frac{(3-\sqrt{3})}{2}\right]$, or equivalently, $\Delta T C<0$ if $q_{D}<\frac{(3-\sqrt{3})}{2}\left(I_{u}-I_{d}\right)$. Q.E.D. 